\title{
Consenso latino-americano de hipertensão em pacientes com diabetes tipo 2 e síndrome metabólica
}

\author{
Latin American consensus on hypertension in patients \\ with diabetes type 2 and metabolic syndrome
}

Patricio López-Jaramillo', Ramiro A. Sánchez², Margarita Diaz ${ }^{3}$, Leonardo

Cobos $^{4}$, Alfonso Bryce ${ }^{5}$, Jose Z. Parra-Carrillo', Fernando Lizcano ${ }^{7}$, Fernando

Lanas $^{8}$, Isaac Sinay ${ }^{9}$, Iván D. Sierra ${ }^{10}$, Ernesto Peñaherrera' ${ }^{11}$, Mario Bendersky ${ }^{12}$,

Helena Schmid ${ }^{13}$, Rodrigo Botero ${ }^{14}$, Manuel Urina ${ }^{15}$, Joffre Lara ${ }^{16}$, Milton C.

Foss $^{17}$, Gustavo Márquez ${ }^{18}$, Stephen Harrap ${ }^{19}$, Agustín J. Ramírez ${ }^{2}$, Alberto

Zanchetti ${ }^{20}$, em nome do Grupo de Especialistas da América Latina

\section{RESUMO}

O presente documento foi preparado por um grupo de especialistas, membros das Sociedades de Cardiologia, Endocrinologia, Medicina Interna, Nefrologia e Diabetes dos países da América Latina, para que sirva de diretriz para médicos que cuidam de pacientes com diabetes, hipertensão e fatores de risco concomitantes ou complicações de ambas as condições. Embora o conceito de síndrome metabólica seja atualmente muito discutido, a alta prevalência na América Latina do conjunto de alterações metabólicas que a compõem sugere que a síndrome metabólica é uma entidade nosográfica útil no contexto da medicina latino-americana. Devido a isso, no presente documento presta-se especial atenção a essa síndrome com a finalidade de alertar aos médicos sobre uma população particularmente de alto risco, que, por ser subestimada, não é tratada de forma adequada para os fatores de risco que constituem a síndrome metabólica. As recomendações deste documento são o resultado de apresentações e debates que ocorreram durante um encontro de dois dias em Bucaramanga (Colômbia), em outubro de 2012. Todos os participantes aprovaram as decisões finais. Os autores reconhecem que a publicação e difusão das diretrizes não serão suficientes para alcançar as mudanças recomendadas tanto em estratégias diagnósticas como terapêuticas, por isso programaram intervenções que permitirão identificar as barreiras do conhecimento, as atitudes e comportamento, o que permitirá tanto aos médicos como aos pacientes uma adequada adesão às recomendações sugeridas nestas diretrizes. Arq Bras Endocrinol Metab. 2014;58(3):205-25

Descritores

Hipertensão arterial; diabetes; síndrome metabólica; Consenso Latino-Americano

\begin{abstract}
The present document has been prepared by a group of experts, members of cardiology, endocrinology, internal medicine, nephrology and diabetes societies of Latin American countries, to serve as a guide to physicians taking care of patients with diabetes, hypertension and comorbidities or complications of both conditions. Although the concept of metabolic syndrome is currently disputed, the higher prevalence in Latin America of that cluster of metabolic alterations has suggested that metabolic syndrome is a useful nosography entity in the context of Latin American medicine. Therefore, in the present document, particular attention is paid to this syndrome in order to alert physicians on a particular high-risk population, usually underestimated and undertreated. These recommendations result from presentations and debates by discussion panels during a 2-day conference held in Bucaramanga, in October 2012, and all the participants have approved the final conclusions. The authors acknowledge that the publication and diffusion of guidelines do not suffice to achieve the recommended changes in diagnostic or therapeutic strategies, and plan suitable interventions overcoming knowledge, attitude and behavioural barriers, preventing both physicians and patients from effectively adhering to guideline recommendations. Arq Bras Endocrinol Metab. 2014;58(3):205-25
\end{abstract}

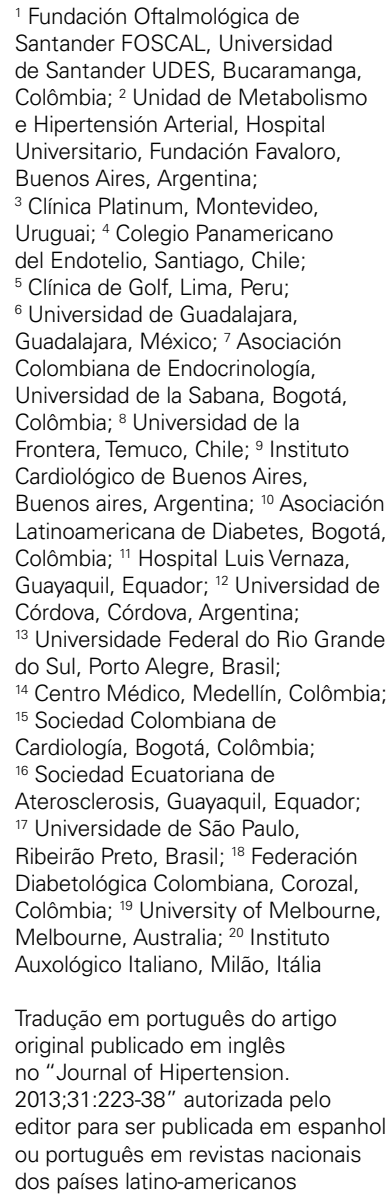

Tradução em português do artigo original publicado em inglês no "Journal of Hipertension. 2013;31:223-38" autorizada pelo editor para ser publicada em espanhol ou português em revistas nacionais dos países latino-americanos

\section{Correspondência para:} Helena Schmid Hospital de Clínicas de Porto Alegre, Serviço de Medicina Interna Av. Ramiro Barcelos, 2350 90035-903 - Porto Alegre, RS, Brasil schmidhelena@yahoo.com.br

Recebido em 29/Set/2013 Aceito em 6/Mar/2014 


\section{INTRODUÇÃO}

A hipertensão arterial, o diabetes e o conjunto de sinais que compõem a condição denominada de síndrome metabólica são altamente frequentes na América Latina e ocorrem frequentemente como condições associadas. O desenvolvimento de recomendações diagnósticas e terapêuticas preparadas por meio do trabalho conjunto de especialistas de diferentes áreas da medicina é desejável, considerando as baixas taxas de controle alcançadas para essas doenças no mundo real e os benefícios que se pode esperar quando se alcançam objetivos razoáveis. Os recursos para os cuidados da saúde, as prioridades para a aplicação desses recursos, o nível socioeconômico da população e as prevalências de hipertensão, diabetes tipo 2 e outras doenças relacionadas variam consideravelmente em diferentes regiões do mundo, também em diferentes países de uma mesma região, e, além do mais, em diferentes áreas de um mesmo país. Para tanto, as recomendações, para serem implementadas de forma útil na prática médica diária, devem considerar as características particulares médicas e sociais da região ou do país onde elas deverão ser aplicadas e devem ser custo-efetivas em termos das necessidades locais e das possibilidades financeiras e técnicas. Por essas razões, a Organização Mundial da Saúde (OMS), a Sociedade Internacional de Hipertensão (ISH) (1) e a Sociedade Europeia de Hipertensão (ESH) propuseram, junto com a Sociedade Europeia de Cardiologia (ESC) (2), em diferentes documentos, a necessidade de desenvolver diretrizes regionais. Além disso, a aceitação e o uso das recomendações regionais provavelmente serão melhores se os médicos e especialistas locais estiverem participando do desenvolvimento e subsequente difusão e implementação das diretrizes $(3,4)$. Por esse motivo, este documento foi preparado por um grupo de especialistas, membros de Sociedades Nacionais e Latino-Americanas de Cardiologia, Endocrinologia, Nefrologia, Medicina Interna e Diabetes, para servir como diretriz para os médicos responsáveis pelos cuidados dos pacientes com diabetes, hipertenão e comorbidades, ou das complicações das duas condições. Apesar de o conceito de "síndrome metabólica" ser atualmente controvertido, a alta prevalência na América Latina do grupo de alterações metabólicas que a compõem torna a síndrome metabólica uma entidade nosográfica útil no contexto da medicina latino-americana. Para tanto, no presente documento se presta especial atenção a essa síndrome, com a finalidade de alertar os médicos sobre uma população particular de alto risco, geralmente subestimada e subtratada.

Essas recomendações são o resultado das apresentações e dos debates dos painéis de discussão que ocorreram durante um evento de dois dias, em Bucaramanga (Colômbia), em outubro de 2012. Os consultores e moderadores das sessões plenárias foram os doutores Stephen Harrap e Alberto Zanchetti, e todos os participantes aprovaram as conclusões finais.

Os autores reconhecem que a publicação e a difusão das diretrizes não são suficientes para alcançar as mudanças recomendadas no diagnóstico e nas estratégias terapêuticas e pretendem programar ações apropriadas que permitirão superar as barreiras comportamentais tanto dos médicos como dos pacientes, o que, de maneira efetiva, poderá levar à adesão às recomendações das diretrizes $(5,6)$.

Uma grande diversidade de características socioeconômicas é encontrada em países da América Latina, e isso se reflete em diferenças na mortalidade e morbidade cardiovascular. De modo diverso ao que ocorreu nos Estados Unidos e na Europa Ocidental, na maioria dos países latino-americanos a taxa de mortalidade cardiovascular tem aumentado nas últimas décadas do século XX e início do século XXI, com exceção da Argentina e Uruguai. Mesmo nestes últimos países, no entanto, a morbidade cardiovascular e a prevalência de fatores de risco cardiovascular têm persistido inalteradas ou aumentaram, especialmente a hipertensão arterial, a obesidade, a síndrome metabólica e o diabetes $(7,8)$. De fato, anos antes do aumento da corrente de doença cardiovascular, ocorreram as mudanças de estilo de vida na região, especialmente dos hábitos alimentares tradicionais para modelos ocidentais de nutrição, o que pode ter facilitado a expressão genética dessas doenças (9). O padrão de morbidade é ainda mais complicado pelo fenômeno da progressiva migração da população rural para as áreas urbanas, o que aumenta a periferia urbana, composta por uma população com poucos recursos individuais, favorecendo a presença de fatores de risco emergentes como aculturação, violência, estresse e desnutrição (7).

\section{PREVALÊNCIA DE HIPERTENSÃO ARTERIAL NA AMÉRICA LATINA}

Os fatores de risco cardiovascular são definidos como características biológicas ou estilos de vida que aumentam a probabilidade (risco) de morbidade e mortalidade cardiovascular (10). 
Como fatores de risco cardiovascular, a hipertensão geralmente integra um conjunto de fatores de risco definidos operacionalmente como síndrome metabólica. Entre esses fatores de risco, a hipertensão arterial é a primeira causa de mortalidade em âmbito mundial e a terceira causa de incapacidade induzida por doença, após desnutrição e doenças sexualmente transmissíveis (11).

A tabela 1 mostra a prevalência, o conhecimento, o tratamento e o controle da hipertensão arterial na América Latina. A prevalência de hipertensão (12-14) foi semelhante na Argentina (25-36\%), Uruguai (30\%), Paraguai (21-30\%) e o sul do Brasil (31-33\%). No Chile (15), foram encontradas diferenças relacionadas ao nível socioeconômico (baixas condições: $24,5 \%$, altas condi- ções 17,9\%). No México, foram encontradas diferenças dependendo das zonas de habitação: $30 \%$ nas zonas urbanas e $11,7 \%$ nas zonas rurais (16). Um estudo recente (17), Prospectivo Urbano Rural Epidemiológico (PURE), incluiu 153.996 adultos (35-70 anos) de 628 comunidades rurais e urbanas de países com diferentes níveis de ingresso financeiro: três países com ingresso alto (PIA), 10 países de ingressos médios altos (PIMA), 3 países de ingressos médios baixos (PIMB) e quatro países de baixa renda (PIB), de várias partes do mundo. A hipertensão foi definida quando os indivíduos relataram tratamento para a hipertensão ou tinham uma pressão sanguínea média (PSM) superior a 140/90 $\mathrm{mmHg}$ em duas medidas de pressão arterial $(\mathrm{PA}) \mathrm{em}$

Tabela 1. Taxas de conhecimento, tratamento e controle da hipertensão arterial na América Latina

\begin{tabular}{|c|c|c|c|c|c|c|c|c|}
\hline País & Cidade/Local & $\begin{array}{c}\text { Ano de } \\
\text { publicação }\end{array}$ & $\begin{array}{l}\text { Idade } \\
\text { (anos) }\end{array}$ & $\begin{array}{c}\text { Número } \\
\text { total }\end{array}$ & $\begin{array}{c}\text { Pacientes } \\
\text { hipertensos } \\
(\%)\end{array}$ & $\begin{array}{c}\% \\
\text { Conhecimento }\end{array}$ & $\%$ Tratados & $\%$ Controlados \\
\hline \multirow[t]{9}{*}{ Argentina } & La Plata & 1988-1989 & $15-75$ & 6386 & 32,3 & $44,0(42,8-45,2)$ & $33,1(31,0-35,2)$ & $5,0(4,3-5,4)$ \\
\hline & Rauch & 1992 & $15-75$ & 1523 & 35,7 & $36,5(35,5-37,5)$ & $32,7(31,1-32,9)$ & $4,0(2,6-6,0)$ \\
\hline & Lujan & 1995 & $18-79$ & 2475 & 24,6 & $56,9(55,7-58,1)$ & $54,2(53,0-55,4)$ & $23,0(22,0-24,0)$ \\
\hline & Córdoba & 1999 & $15-85$ & 6875 & 29,9 & $54,9(52,4-57,4)$ & $43,0(40,5-45,5)$ & $13,0(11,3-14,8)$ \\
\hline & Dean Funes & 1999 & $20-70$ & 750 & 29,7 & $19,3(14,4-25,1)$ & $6,7(3,8-10,8)$ & - \\
\hline & Rosario & 1999 & $21-65$ & 2071 & 31,3 & $79,7(78,1-81,3)$ & $47,8(45,8-49,8)$ & $25,3(23,3-26,8)$ \\
\hline & Rural/Urbana & NP & $19-99$ & 10415 & 26,0 & $50,8(48,6-53,0)$ & $41,7(39,6-43,8)$ & $13,0(11,3-14,8)$ \\
\hline & Buenos Aires & 2005 & $25-64$ & 1482 & 29,0 & $64,1(59,9-68,2)$ & $41,6(37,5-45,8)$ & $18,0(14,8-21,2)$ \\
\hline & Porto Alegre & 1994 & $>18$ & 1091 & 29,7 & $39,1(33,4-44,6)$ & $13,8(10,3-18,1)$ & - \\
\hline Brasil & São Paulo (NE) & 2001 & $>18$ & 688 & 31,5 & $77,0(70,7-82,4)$ & $61,8(54,9-68,3)$ & $17,0(12,3-22,7)$ \\
\hline Colômbia & Bogotá & 2005 & $25-64$ & 1553 & 13,5 & $68,8(62,5-75,5)$ & $55,0(48,2-61,8)$ & $30,6(25,8-35,5)$ \\
\hline \multirow[t]{4}{*}{ Chile } & Concepción & 1988 & $>14$ & 10139 & 18,6 & $65,7(63,5-67,8)$ & $30,0(27,9-32,2)$ & $7,5(6,4-8,7)$ \\
\hline & Concepción & 2004 & $>15$ & 8472 & 21,6 & 66,6 (NR) & 59,9 (NR) & 30,7 (NR) \\
\hline & Valparaíso & 1999 & $25-69$ & 3120 & 11,0 & $44,0(42,2-45,8)$ & $22,0(20,5-23,5)$ & - \\
\hline & Santiago & 2005 & $25-69$ & 1655 & 23,8 & $61,1(55,4-64,7)$ & $43,0(38,8-47,7)$ & $20,3(16,4-24,2)$ \\
\hline Cuba & Nacional & NR & NR & 102235 & 39,7 & 70,2 (NR) & - & $39,7(39,2-40,2)$ \\
\hline \multirow[t]{2}{*}{ Equador } & Nacional & 1999 & $>18$ & 10605 & 28,6 & $41,0(37,7-43,4)$ & $23,0(22,3-23,8)$ & $7,0(6,5-7,5)$ \\
\hline & Quito & 2005 & $25-64$ & 1638 & 8,6 & $67,6(60,2-74,9)$ & $51,8(43,9-59,8)$ & $28,0(19,9-36,1)$ \\
\hline \multirow[t]{6}{*}{ México } & Guadalajara & 1980 & $>16$ & 4031 & 21,5 & $51,3(47,9-54,7)$ & $45,6(42,3-49,1)$ & $7,6(6,0-9,6)$ \\
\hline & Aguas Calientes & 1997 & $>25$ & 6128 & 26,8 & $75,0(73,9-76,1)$ & $37,0(35,8-39,2)$ & - \\
\hline & Durango & 1998 & $>20$ & 5802 & 21,9 & $69,1(67,9-70,3)$ & - & - \\
\hline & Norte (Rural) & 2000 & $25-64$ & 815 & 6,8 & $41,0(37,5-44,5)$ & - & - \\
\hline & Nacional & 2000 & $25-64$ & 38377 & 31,3 & $43,0(42,1-43,9)$ & $20,3(17,9-22,9)$ & $4,9(3,7-6,3)$ \\
\hline & México DF & 2005 & $25-64$ & 1722 & 11,6 & $75,7(70,1-81,2)$ & $65,7(60,4-70,9)$ & $41,0(36,2-45,8)$ \\
\hline Paraguai & Nacional & 1995 & $18-74$ & 9880 & 30,4 & $11,0(10,4-11,7)$ & $5,5(5,1-6,0)$ & 0,0 \\
\hline Peru & Lima & 2005 & $25-64$ & 1652 & 12,5 & $53,1(46,5-59,6)$ & $28,8(24,0-33,5)$ & $12,0(8,4-15,7)$ \\
\hline Uruguai & Minas & $\mathrm{NR}$ & $>18$ & 560 & 37,3 & $78,5(72,2-83,9)$ & $47,4(40,4-54,3)$ & $16,3(11,5-22,0)$ \\
\hline \multirow[t]{3}{*}{ Venezuela } & Barquisimeto & 1994 & $>20$ & 15000 & 23,5 & $61,3(60,5-62,1)$ & $46,0(44,4-47,6)$ & $20,6(19,2-22,0)$ \\
\hline & Barquisimeto & 2000 & $>20$ & 7424 & 36,8 & $45,7(44,7-46,8)$ & $22,9(21,9-23,9)$ & $4,5(4,0-5,0)$ \\
\hline & Maracaibo & 2005 & $25-64$ & 1848 & 24,6 & $72,0(67,8-76,2)$ & $48,9(44,2-53,5)$ & $20,7(17,4-24)$ \\
\hline
\end{tabular}

Conhecimento, tratamento e controle da hipertensão fazem referência a pacientes que sabem ter hipertensão arterial, que estão recebendo tratamento e que alcançaram valores < de 140/90 mmHg. Os valores nestes casos são dados como percentual da população de hipertensos (95\% IC). IC: intervalo de confiança; NR: não reportado. 
repouso sentado usando um dispositivo digital automatizado. Foi observado que $40,7 \%$ dos participantes tinham hipertensão, com 13,3\% tendo a PA mínima em 160/100 mmHg e 4,4\%, uma PA mínima de 180/110 mmHg. Das pessoas com hipertensão, 46,4\% estavam cientes dessa condição, $40,6 \%$ estavam em tratamento farmacológico, mas apenas $13,1 \%$ tinham pressão arterial controlada $(<140 / 90 \mathrm{mmHg})$. Globalmente, a prevalência de hipertensão foi semelhante nos PIMA $(49,6 \%)$, PIA $(40,7 \%)$ e PIMB $(39,6 \%)$, mas menor nos PIB $(32,2 \%)$. As porcentagens de consciência da doença foram: PIA - 49,1\%, PIMA - 52,4\%, PMIB - 43,5\% e PIB $-40,8 \%$ (tendência $=\mathrm{P}<0,001$ ), de tratamento 46,$8 ; 48,3 ; 36,8$ e $31,7 \%$, respectivamente (tendência $=\mathrm{P}<0,001)$ e controle, de $19,15,5,9,9$ e $12,7 \%$, respectivamente (tendência $=\mathrm{P}<0,001$ ), o que mostra que essas porcentagens foram inversamente relacionadas com o nível econômico do país.

A prevalência, o conhecimento, o tratamento e o controle da hipertensão foram melhores em áreas urbanas do que em comunidades rurais nos PIB e nos PIMB, mas isso não ocorreu nos PIA e PIMA. Em geral, 12,5\% dos pacientes hipertensos tratados receberam dois ou mais medicamentos para baixar a PA, com uma tendência decrescente a partir dos países ricos para os países pobres (PIA 18,1\%, PIMA 14,5\%, PIMB 14,1\%, PIB 1,6\%; P < 0,0001). Menor nível de educação foi fortemente associado com menores taxas de conhecimento, tratamento e controle da pressão arterial nos países de condição econômica inferior, mas isso era menos evidente nos outros países. A prevalência de hipertensão foi maior em participantes com diabetes $(63 \%)$, apesar de que o conhecimento sobre a doença era de $74,4 \%$, e o percentual dos diabéticos hipertensos que recebia o tratamento era de $69,3 \%$, sendo a taxa de controle de apenas $23,3 \%$. Uma análise por região indicou que a prevalência de hipertensão foi mais elevada na África $(56,6 \%)$, segui- da pela Malásia (46,5\%) e América do Sul (46,5\%). Os países da América do Sul incluídos no estudo PURE foram Argentina, Brasil, Chile e Colômbia. A tabela 2 mostra as características dos indivíduos estudados em cada país. Os percentuais de conhecimento, tratamento e controle da hipertensão nos quatro países da América do Sul foram, em média, 57,0, 52,8 e 18,3\%, respectivamente (Chow et al. JAMA, 2013, in press).

A partir dos dados de avaliação, pôde-se concluir que, em todo o mundo, detecção e tratamento da hipertensão são deficientes e que a maioria dos doentes tratados tem mau controle da PA. Esses resultados foram comuns a todos os países independentemente do nível socioeconômico, embora tratamento e controle foram significativamente piores nos PIB. Em função disso, esforços sistemáticos devem ser realizados para a implementação, em nível comunitário, de programas de detecção eficientes, por meio da implementação de estratégias baseadas en algoritmos simples que permitam um melhor tratamento e controle da PA. Esses programas nos parecem ser cruciais para reduzir todas as doenças relacionadas com a hipertensão arterial.

\section{PREVALÊNCIA DA SÍNDROME METABÓLICA NA AMÉRICA LATINA}

$\mathrm{Na}$ América Latina, a prevalência dos componentes da síndrome metabólica, como a hipertensão arterial, parece estar aumentando. Estudos locais (18-41) têm relatado que a prevalência de síndrome metabólica em adultos oscila entre 25 e $45 \%$, com diferenças importantes entre as zonas urbanas e rurais, porém as comparações são difíceis devido às diferentes definições utilizadas. Em pacientes com infarto agudo de miocárdio ou com acidente vascular encefálico (27), a prevalência foi tão alta como $75 \%$, independentemente dos critérios de diagnóstico utilizados para síndrome metabólica (International Diabetes Federation, IDF, ou Painel de Tratamento do Adulto, ATP III).

Tabela 2. Características dos participantes da América do Sul por país

\begin{tabular}{|c|c|c|c|c|c|c|c|c|c|}
\hline País & Número & $\begin{array}{l}\text { Recrutamento } \\
\text { (anos) }\end{array}$ & $\begin{array}{c}\text { Rural } \\
{[\mathrm{N}=(\%)]}\end{array}$ & $\begin{array}{l}\text { Feminino } \\
{[\mathrm{N}=(\%)]}\end{array}$ & $\begin{array}{c}\text { Idade } \\
\text { (anos, SD) }\end{array}$ & $\begin{array}{c}\text { PAS } \\
\text { (mmHg, SD) }\end{array}$ & $\begin{array}{c}\text { PAD } \\
\text { (mmHg, SD) }\end{array}$ & $\begin{array}{c}\mathrm{PA} \geq 140 / 90 \\
\mathrm{mmHg} \\
{[\mathrm{n}=(\%)]}\end{array}$ & $\begin{array}{c}P A \geq 160 / 100 \\
m m H g \\
{[n=(\%)]}\end{array}$ \\
\hline Argentina & 7483 & 2006-2009 & $3894(52,0)$ & $4603(61,5)$ & $51(10,0)$ & $135,6(21,7)$ & $28,75(12,5)$ & $3804(50,8)$ & $2455(32,6)$ \\
\hline Brasil & 5566 & 2005-2009 & $1300(23,4)$ & $3076(53,3)$ & $52(9,4)$ & $132,33(23,8)$ & $86,63(38,0)$ & $2928(52,6)$ & $2274(37,5)$ \\
\hline Chile & 3112 & 2006-2009 & $643(20,0)$ & $2135(66,5)$ & $52(9,8)$ & $130,80(22,2)$ & $82,11(20,4)$ & $1499(46,7)$ & $1058(30,7)$ \\
\hline Colômbia & 7417 & 2005-2009 & $3964(53,4)$ & $4759(64,2)$ & $51(9,7)$ & $128,77(23,3)$ & $81,05(16,9)$ & $2781(37,5)$ & $1737(23.3)$ \\
\hline
\end{tabular}

PA $\geq 140 / 90$ mmHg: autorrelato de hipertensão ou valores de PA $\geq 140 / 90 \mathrm{mmHg} ; \mathrm{PA} \geq 160 / 100 \mathrm{mmHg}$ : autorrelato de hipertensão ou valores de PA $\geq 160 / 100 \mathrm{mmHg}$. (Adaptada de Chow et al. JAMA 2013, in press.) 
Uma metanálise recente, que incluiu 12 estudos transversais, realizados nos países latino-americanos (42), mostrou que a prevalência geral (média ponderada) da síndrome metabólica (SM), segundo os critérios do ATP III, foi $24,9 \%$ (range: $18,8-43,3 \%$ ). A SM foi ligeiramente mais frequente em mulheres $(25,3 \%)$ que em homens $(23,3 \%)$ e o grupo de idade com maior prevalência foi o acima dos 50 anos. Os componentes mais frequentes da síndrome metabólica foram as baixas concentrações de colesterol em lipoproteínas de alta densidade (HDL-colesterol; 62,9\%) e obesidade abdominal $(45,8 \%)$. Achados similares foram reportados no estudo multicêntrico CARMELA realizado em capitais de países da América Latina (21).

\section{PREVALÊNCIA DE DIABETES TIPO 2 NA AMÉRICA LATINA}

Entre a população urbana da América Latina, a prevalência de diabetes encontra-se entre 4 e $8 \%$ e é maior nos países ou zonas com um nível socioeconômico baixo ou médio (Tabela 3). No entanto, os dados são escassos e a porcentagem de pacientes sem confirmação do diagnóstico é ao redor de 30-50\% e pode ser maior nas zonas rurais. O estudo CARMELA (12) realizado em sete cidades de países da América Latina durante o ano 2005 encontrou uma prevalência de diabetes que foi próxima do dobro dos valores anteriormente reportados. A prevalência de diabetes foi de $6 \% \mathrm{em}$ Barquisimeto, Venezuela, $8 \%$ em Bogotá, Colômbia, 6,2\% em Buenos Aires, Argentina, 8,9\% no México DF, México, e 7,2\% em Santiago, Chile. Como em outras áreas do mundo, a crescente prevalência de

Tabela 3. Prevalência de diabetes melito na América Latina

\begin{tabular}{lc}
\hline Local & $\%$ \\
\hline Argentina & $5,0^{\mathrm{a}}$ \\
Bolívia & $7,2^{\mathrm{b}}$ \\
Brasil & $7,6^{\mathrm{c}}$ \\
Colômbia & $7,3^{\mathrm{b}}$ \\
Cuba & 4,5 \\
Chile & $3,9^{\mathrm{b}}$ \\
Jamaica & $13,4^{\mathrm{a}}$ \\
México & $8,6^{\mathrm{b}}$ \\
Paraguai & $6,2^{\mathrm{b}}$ \\
Uruguai & $7,0^{\mathrm{b}}$ \\
Venezuela & $4,4^{\mathrm{b}}$ \\
\hline
\end{tabular}

\%: estudos populacionais publicados até 2010. ${ }^{\mathrm{a}}$ OMS 1980; ' OMS 1985; ' ADA-OMS 1997. diabetes na América Latina se deve, principalmente, às mudanças no estilo de vida: menos atividade física, maior consumo de calorias e aumento da prevalência de sobrepeso/obesidade, decorrentes da acelerada urbanização.

Em indivíduos com diabetes, a prevalência de hipertensão arterial é 1,5-3 vezes maior que nos indivíduos não diabéticos com idade similar, associação particularmente alta em países de médios e baixos ingressos financeiros $(12,43-48)$.

\section{PREVALÊNCIA DE SOBREPESO E OBESIDADE NA AMÉRICA LATINA}

Diferentes avaliações realizadas na América Latina (4461) reportam uma importante prevalência de pessoas com sobrepeso (IMC 25-29,9 kg/m²) e obesidade $\left(\right.$ IMC $\left.\geq 30 \mathrm{~kg} / \mathrm{m}^{2}\right)$.

Em Rosário, Argentina (48), a prevalência de sobrepeso foi de $40 \%$ e a de obesidade, de $29 \%$. Na cidade do Rio de Janeiro (55), o sobrepeso esteve presente em $40 \%$ e a obesidade em $21 \%$ da população estudada. No México $(43,49)$, a prevalência de sobrepeso foi de $37 \%$ nas zonas rurais e $48 \%$ no México DF, e a obesidade foi ao redor de $21 \%$ (rural: 7\%, DF: 29\%). Em Cuba (54), o sobrepeso e a obesidade em conjunto alcançaram cifras ao redor de $22 \%$. Em muitos estudos, houve uma forte associação entre obesidade e hipertensão arterial com $40 \%$ dos indivíduos apresentando hipertensão arterial e obesidade.

As estimativas de prevalência específica de obesidade têm demonstrado uma grande variabilidade entre as populações latino-americanas, que vão desde 9,9 até $35,7 \%$ (57). As mulheres $(23,33,37,51)$ e as pessoas que habitam as zonas urbanas (4l) têm sido identificadas como os grupos predominantemente afetados. Além disso, a obesidade tem sido relacionada de forma independente com baixo nível socioeconômico e baixos níveis de educação $(49,53)$, o que contribui para as desigualdades de saúde observadas na região $(59,60)$. Por outro lado, existe evidência de uma tendência secular para aumento da prevalência de obesidade nos países economicamente mais desenvolvidos da América Latina (61).

Assim como nos adultos, a obesidade tem se convertido também em um problema de saúde nas crianças da América Latina, devido ao alto risco de persistência de obesidade na idade adulta e associar-se com o desenvolvimento de hipertensão arterial $(22,50,51)$. 


\section{SÍNDROME METABÓLICA, DIABETES E HIPERTENSÃO ARTERIAL: DEFINIÇÃO, DIAGNÓSTICO E AVALIAÇÃO CLÍNICA}

\section{Síndrome metabólica}

Como mencionado anteriormente, o conceito de síndrome metabólica é controvertido principalmente porque é difícil provar que o risco cardiovascular das pessoas com síndrome metabólica é maior do que aquele que corresponde à soma do risco atribuível a cada um de seus componentes. A síndrome metabólica é um quadro clínico com características facilmente detectáveis e, apesar disso, permanece insuficientemente diagnosticada, tendo a vantagem de que, com um único termo, agrupa um conjunto de alterações metabólicas muito prevalentes na América Latina. Em função disso, é um instrumento útil para identificar indivíduos com alto risco de doença cardiovascular (DCV) e de diabetes. Atualmente, é bem aceito o conceito de que todos os componentes da síndrome metabólica estão associados com resistência à ação da insulina $(26,62,63)$.

O recente consenso do Grupo de Trabalho em Epidemiologia e Prevenção da Federação Internacional de Diabetes (FID), do Instituto Nacional de Coração, Pulmão e Sangue dos Estados Unidos, da Associação Americana de Coração, da Federação Mundial de Coração, da Sociedade Internacional de Aterosclerose e da Associação Internacional para o Estudo da Obesidade (62) propôs que a presença de três dos cinco critérios seguintes são suficientes para o diagnóstico de síndrome metabólica:

1) Circunferência da cintura aumentada, cuja definição é específica para cada população e para cada país;

2) Triglicerídios iguais ou maiores que $150 \mathrm{mg} / \mathrm{dL}$, ou tratamento farmacológico para triglicerídios séricos elevados;

3) Redução de HDL-colesterol a menos de 40 $\mathrm{mg} / \mathrm{dL}$ em homens e menos de $50 \mathrm{mg} / \mathrm{dL}$ em mulheres. ( $\mathrm{O}$ tratamento com medicamentos para diminuir o HDL-colesterol tal como ácido nicotínico é um indicador alternativo);

4) Pressão arterial no limite superior da normalidade ou hipertensão (PAS $\geq 130 \mathrm{mmHg} \mathrm{e} / \mathrm{ou}$ $\mathrm{PAD} \geq 85 \mathrm{mmHg}$ ) ou estar em tratamento farmacológico com anti-hipertensivos;

5) Glicemia em jejum igual ou maior que 100 $\mathrm{mg} / \mathrm{dL}$ ou estar em tratamento farmacológico com hipoglicemiantes.
Vários autores consideram a obesidade central (abdominal) como o principal fator causal na síndrome metabólica e esta deveria ser incluída como obrigatória no diagnóstico. Para definir o ponto de corte da obesidade abdominal na América Latina, um estudo recente (64), o qual incluiu as capitais de vários países, recomendou valores de cintura iguais ou maiores que $94 \mathrm{~cm}$ para os homens e $88 \mathrm{~cm}$ para as mulheres. No entanto, vários estudos independentes realizados em diferentes populações da América Latina têm demonstrado que os pontos de corte sugeridos pela IDF $(90 \mathrm{~cm}$ para homens e $80 \mathrm{~cm}$ para mulheres) são os que melhor se relacionam com a presença dos outros componentes da síndrome metabólica $(27,28,30,34,36)$.

Embora não existam na América Latina estudos de coorte que avaliem a relação dos pontos de corte da circunferência da cintura com o desenvolvimento de diabetes ou de doenças cardiovasculares, é de se esperar que, como ocorre com a maioria dos outros fatores de risco cardiovascular, a relação seja contínua e qualquer ponto de corte se baseie em convenções arbitrárias. A escolha dos autores deste documento de consenso é a de usar os valores de corte propostos pela IDF $(90 \mathrm{~cm}$ para homens e $80 \mathrm{~cm}$ para mulheres).

Os fatores de risco que se associam com um maior risco de síndrome metabólica estão enumerados a seguir:

1) Antecedentes familiares de diabetes melito tipo 2;

2) Diabetes melito gestacional;

3) Macrossomia;

4) Baixo peso ao nascer;

5) Desnutrição infantil;

6) Alta mortalidade perinatal e/ou presença temporária de doença cardiovascular precoce em familiares de primeira ordem;

7) Hábito sedentário;

8) Dieta rica em gorduras animais;

9) Raça;

10) Baixo nível socioeconômico;

11) História de dislipidemia, obesidade e hipertensão;

12) Hiperandrogenismo na mulher; e

13) Acantosis nigricans.

O diagnóstico de síndrome metabólica pode ser útil para a identificação de indivíduos nos quais se pode realizar prevenção primária de diabetes melito, hipertensão e DCV. Espera-se que um aumento na detecção melhore a atenção tanto dos pacientes como dos médicos quanto ao risco cardiometabólico que correm esses indivíduos e, em consequência, seja útil para reforçar a motivação para realizar as alterações necessárias 
nos estilos de vida e na redução de peso corporal. No momento não há estudos que demonstrem que o tratamento da síndrome metabólica com medicamentos seja útil, no entanto, está claro que, quando a PA, os lipídios e a glicose plasmática estão acima dos valores aceitos para definir hipertensão, dislipidemia e diabetes, o tratamento medicamentoso anti-hipertensivo, antilipídico e antidiabético deve ser iniciado.

\section{Diabetes tipo 2}

Os critérios para o diagnóstico de diabetes melito tipo 2, aprovados e recomendados pelo Consenso Latino-Americano, são os seguintes:

1) Glicose plasmática em jejum igual ou maior a $126 \mathrm{mg} / \mathrm{dL}$ em duas leituras sucessivas;

2) Glicose plasmática igual ou maior a $200 \mathrm{mg} / \mathrm{dL}$ depois de 120 minutos de administrar $75 \mathrm{~g}$ de glicose na prova da sobrecarga oral de glicose;

3) Glicose plasmática igual ou maior a $200 \mathrm{mg} / \mathrm{dL}$ em qualquer momento do dia, na presença de sintomas.

Esses são os mesmos critérios da Associação Americana de Diabetes (ADA) (65), os quais foram adotados pelo Consenso, salientando-se que foi destacada a importância do teste de tolerância oral à glicose (TTOG) como uma ferramenta diagnóstica mais específica. Considerou-se que é bem-vindo o termo "pré-diabetes" e que os menores pontos de corte para definir intolerância à glicose [glicose em jejum alterada (GAA: 100-125 $\mathrm{mg} / \mathrm{dL}$ ) e/ou TTOG alterado (TTOG:140-199 mg/ dL) podem melhorar a detecção de diabetes $(66,67)$, mas o custo-efetividade dessas estratégias em termos de implementação de programas de tratamento e prevenção das complicações é, no entanto, desconhecido (68), de modo que o Consenso preferiu recomendar a classificação da $\operatorname{ADA}(65)$.

\section{Hipertensão: classificação e diagnóstico}

Depois de considerar as classificações propostas pelo Sétimo Relatório do Comitê Nacional Conjunto em Prevenção, Detecção, Avaliação e Tratamento da Hipertensão Arterial (69), as diretrizes da ESH-ESC 2007 sobre o manejo da hipertensão (70), a reavaliação de 2009 das Diretrizes Europeias (71) e o Consenso Latino-Americano anterior de Hipertensão Arterial (10), foi decidido, como mostra a tabela 4, manter o conceito de que a hipertensão arterial se diagnostica quando os valores de pressão arterial são iguais ou maiores a $140 / 90 \mathrm{mmHg}$ quando medida em consul- tório médico ou em uma clínica. Acima desse valor, a hipertensão pode ser subdividida em graus 1,2 e 3. Essa classificação também se aplica para a hipertensão sistólica isolada, a qual deve ser diagnosticada e tratada especialmente em pacientes idosos. Os pacientes idosos maiores de 80 anos devem ser diagnosticados como hipertensos quando a PA é igual ou maior a 150/90 mmHg. Em pacientes de idade avançada, a PA também deve ser medida na posição de pé para detectar uma possível queda ortostática anormal.

A hipertensão arterial se classifica como primária, essencial ou idiopática, quando a PA é consistentemente mais alta que o normal, sem causa conhecida, o que representa mais de $90 \%$ de todos os casos. Define-se a hipertensão como secundária quando a PA se eleva como resultado de uma causa subjacente, identificável e, com frequência, corrigível (o restante, ou $10 \%$ dos pacientes hipertensos).

O diagnóstico da hipertensão deve basear-se em ao menos três medidas diferentes de PA, tomadas em ao menos duas visitas separadas ao consultório ou ao hospital. Diagnostica-se hipertensão arterial quando a PA é ao menos de 140 e/ou $90 \mathrm{mmHg}$. Embora os valores obtidos no consultório ou em uma clínica são aqueles em que o diagnóstico e o tratamento se baseiam, existem métodos adicionais de aferição da PA que são úteis em vários casos. A monitorização ambulatorial da PA durante 24 horas (MAPA) está mais relacionada com o prognóstico do que a PA medida no consultório $(72,73)$ e permite detectar dois subgrupos de pacientes hipertensos quando a PA ambulatorial ou do ambiente doméstico e a do consultório são divergentes: a hipertensão do avental branco (hipertensão no consultório e normotensão ambulatorial e doméstica) e a hipertensão (normotensão no consultório e hipertensão ambulatorial e no ambiente doméstico). Os valores de corte para o diagnóstico de hipertensão mediante o MAPA estão indicados na tabela 5 .

Tabela 4. Classificação da pressão arterial e hipertensão recomendada pelo Consenso Latino-Americano

\begin{tabular}{lc}
\hline Pressão arterial & Valor $(\mathbf{m m H g})$ \\
\hline Ótima & $<120 / 80$ \\
Normal & $120 / 80-129 / 84$ \\
Normal alta & $130 / 85-139 / 89$ \\
Hipertensão grau 1 & $140 / 90-159 / 99$ \\
Hipertensão grau 2 & $160 / 100-179 / 109$ \\
Hipertensão grau 3 & $\geq 180 / 110$ \\
Hipertensão sistólica isolada & $\geq 140 /<90$ \\
\hline
\end{tabular}


Tabela 5. Hipertensão: critérios de pressão arterial

\begin{tabular}{ll}
\hline Hipertensão & Pressão arterial $\geq 140 / 90 \mathrm{mmHg}$ medida no consultório ou em hospital (média de três medições/visita, durante três visitas) \\
MAPA $24 \mathrm{~h} \geq 130 / 80 \mathrm{mmHg}$, MAPA diurno $\geq 135 / 85 \mathrm{mmHg}$ \\
PA tomada em casa ou autodeterminação $\geq 135 / 85 \mathrm{mmHg}$ \\
Hipertensão do avental branco & Hipertensão no consultório ou no hospital e normotensão ambulatorial ou em casa \\
Hipertensão mascarada & Normotensão no consultório ou no hospital com hipertensão ambulatorial e/ou no ambiente doméstico \\
\hline
\end{tabular}

MAPA: medida da pressão arterial ambulatorial.

Em algumas situações clínicas, o MAPA é muito útil para o diagnóstico de hipertensão, por exemplo, quando se suspeita de hipertensão do avental branco, quando os pacientes com hipertensão marcada não apresentam sinais de lesão de órgão-alvo e quando se observam importantes diferenças nos valores de PA medidos em diferentes visitas. Também existe a indicação para medir a PA em casa, pois se sabe que esse procedimento melhora a adesão. Para tanto, só devem ser utilizados dispositivos automáticos validados e o paciente deve ser instruído a realizar as medidas na posição sentada, depois de vários minutos de repouso, idealmente pela manhã e à tarde. Durante o tratamento, as medidas devem ser realizadas pela manhã, antes de tomar os medicamentos anti-hipertensivos.

No manejo do paciente hipertenso, não só se deve considerar os níveis da pressão arterial como também o risco cardiovascular global. Com a finalidade de estratificar o risco cardiovascular global, devem-se considerar o número de fatores de risco presentes, a ausência ou presença de lesões de órgãos-alvo e as condições clínicas prévias ou simultâneas, incluindo a síndrome metabólica e o diabetes, junto com a classificação de PA que está resumida na tabela 6 .

\section{A hipertensão em pacientes com diabetes}

Nos indivíduos com diabetes, como resultado de alteração da função autonômica e de lesões extensas de órgãos, são frequentes a presença de uma maior variabilidade da pressão arterial, uma marcada resposta ortostática e uma importante deterioração da redução noturna da PA (72). Essas características têm implicações diagnósticas, prognósticas e terapêuticas de modo que se recomenda que o número de medidas da PA para tomada de decisões deva ser maior, a detecção de possível hipotensão para a tomada de decisões também maior, a detecção de hipotensão ortostática deve ser um procedimento de rotina, e a tomada de PA em ambiente do- méstico e sobretudo do MAPA deve realizar-se sempre que possível. A informação atualizada sobre esse tema está disponível (73) e é aconselhável à formação dos médicos na interpretação desses dados.

As recomendações sobre a avaliação diagnóstica nos pacientes com hipertensão e diabetes estão resumidas na tabela 7 . As recomendações para o seguimento são as seguintes:

1) HbAlc (cada 4 meses);

2) Automonitorização da glicose no sangue (cada 24 a 48 horas);

3) Anualmente avaliação do fundo de olho, ECG, microalbuminúria, provas básicas de laboratório;

4) A cada 2 anos, devem ser realizados ecocardiograma e electrocardiograma de esforço (para detectar possível isquemia silenciosa).

Em termos de risco cardiovascular total (ver Tabela 6), a presença de diabetes geralmente se considera que implica nível de alto de risco, porém é razoável pensar que o risco cardiovascular é diferente se o diabetes foi diagnosticado recentemente ou se é de grande duração, na ausência ou em presença de complicações. Em pacientes normotensos com diabetes, não há evidência de que a administração de fármacos redutores da PA seja de algum benefício.

\section{Complicações renais e cardiovasculares em pacientes hipertensos diabéticos}

Os pacientes com diabetes e hipertensão têm um maior risco de doença renal, doença cardíaca coronariana (DCC), acidente vascular encefálico e insuficiência cardíaca. A associação com comorbidades como a dislipidemia, estado protrombótico e disfunção autonômica (74) contribui para aumentar a morbidade e a mortalidade. 
Tabela 6. Estratificação do risco em pacientes com síndrome metabólica, hipertensão e diabetes tipo 2

\begin{tabular}{|c|c|c|c|c|c|c|}
\hline \multirow{2}{*}{$\begin{array}{l}\text { Outros fatores de } \\
\text { risco ou doenças }\end{array}$} & \multicolumn{3}{|c|}{ Normotensão } & \multicolumn{3}{|c|}{ Hipertensão } \\
\hline & Ótima & Normal & Normal alta & Grau 1 & Grau 2 & Grau 3 \\
\hline Sem fatores de risco (FR) & Risco médio & Risco médio & Risco médio & $\begin{array}{l}\text { Risco adicional } \\
\text { baixo }\end{array}$ & $\begin{array}{l}\text { Risco adicional } \\
\text { moderado }\end{array}$ & Risco adicional alto \\
\hline $\begin{array}{l}\text { 1-2 FR ou condições } \\
\text { sociais de risco }\end{array}$ & $\begin{array}{l}\text { Risco adicional } \\
\text { baixo }\end{array}$ & $\begin{array}{l}\text { Risco adicional } \\
\text { baixo }\end{array}$ & $\begin{array}{l}\text { Risco adicional } \\
\text { baixo }\end{array}$ & $\begin{array}{l}\text { Risco adicional } \\
\text { moderado }\end{array}$ & $\begin{array}{l}\text { Risco adicional } \\
\text { moderado }\end{array}$ & $\begin{array}{l}\text { Risco adicional } \\
\text { muito alto }\end{array}$ \\
\hline $\begin{array}{l}\mathrm{FR} \geq 3 \text { ou condições } \\
\text { sociais de risco, LOA ou } \\
\text { SM/DM }\end{array}$ & $\begin{array}{l}\text { Risco adicional } \\
\text { moderado }\end{array}$ & $\begin{array}{l}\text { Risco adicional } \\
\text { moderado }\end{array}$ & Risco adicional alto & Risco adicional alto & Risco adicional alto & $\begin{array}{l}\text { Risco adicional } \\
\text { muito alto }\end{array}$ \\
\hline Condição clínica associada & $\begin{array}{l}\text { Alto risco } \\
\text { adicionado }\end{array}$ & $\begin{array}{l}\text { Alto risco } \\
\text { adicionado }\end{array}$ & $\begin{array}{l}\text { Muito alto risco } \\
\text { adicionado }\end{array}$ & $\begin{array}{l}\text { Muito alto risco } \\
\text { adicionado }\end{array}$ & $\begin{array}{l}\text { Muito alto risco } \\
\text { adicionado }\end{array}$ & $\begin{array}{l}\text { Muito alto risco } \\
\text { adicionado }\end{array}$ \\
\hline
\end{tabular}

DM: diabetes melito; SM: síndrome metabólica; FR: fator de risco; LOA: lesão de órgão-alvo.

Tabela 7. Recomendações de avaliação diagnóstica dos pacientes hipertensos com diabetes melito

\begin{tabular}{ll}
\hline Investigações básicas ou mínimas & História clínica e exame físico \\
& Medida da pressão arterial (conforme ADA) \\
& ECG \\
& Provas laboratoriais: glicemia em jejum e HbA1c, creatinina sérica, perfil de lipídios, enzimas hepáticas, Na+, $\mathrm{K}^{+}$ \\
& Microalbuminúria (conforme ADA) \\
& Fundo de olho (se anormal interconsulta com oftalmologista) \\
& MAPA \\
Investigações opcionais & ECG de esforço (em homens $>40$ anos e em mulheres pós-menopáusicas) \\
& Ecocardiograma com Doppler \\
\hline
\end{tabular}

MAPA: monitorização ambulatorial da pressão arterial; ADA: American Diabetes Association.

\section{Nefropatia diabética}

A prevalência da nefropatia em pacientes com diabetes tipo 2 é de 30-50\% (75). Foram descritas três etapas no seu desenvolvimento (76):

1) Nefropatia incipiente, com uma duração de cerca de 10 anos, cursa com uma taxa supranormal de filtração glomerular (TFG), que se acompanha após em torno de 5 anos de aumento da excreção urinária de albumina (EUA: 30-300 $\mathrm{mg} /$ dia $=$ microalbuminúria $)$. A presença de um aumento da EUA identifica os pacientes diabéticos com alto risco de desenvolver dano renal progressivo e doença cardiovascular.

2) Nefropatia clínica evidente, caracterizada por uma EUA maior que $300 \mathrm{mg} /$ dia (proteinúria), TFG normal ou moderadamente reduzida e hipertensão. Se não tratados, esses pacientes têm um alto risco de desenvolver doença renal terminal (DRT). Sem uma intervenção adequada, essa condição pode progredir rapidamente, e $50 \%$ dos pacientes podem chegar a DRT em
10 anos e $75 \%$ em 20 anos. Ao contrário, as intervenções terapêuticas em ambos os tipos de diabetes diminuem a velocidade de alteração da TFG e a progressão a DRT. Tem sido informado que de 20 a $40 \%$ dos indivíduos com EUA podem progredir para macroalbuminúria e $20 \%$ deles para DRT.

3) Insuficiência renal progressiva que cursa com proteinúria franca $(\geq 300(\mathrm{mg} / \mathrm{dL})$ e uma notável redução da TFG $(<30 \mathrm{ml} / \mathrm{min})$. A macroalbuminúria identifica os pacientes diabéticos com lesão renal histológica substancial e prediz uma queda linear da TFG.

Para a detecção do aparecimento e da progressão da nefropatia diabética, é obrigatória a avaliação da EUA todos os anos desde o início da DM2, e o cálculo da TFG a partir da creatinina sérica mediante o uso de uma das fórmulas atualmente validadas (Modificação da Dieta em Doença Renal, MDRD ou pela fórmula do Grupo Colaborador da Epidemiologia da Doença Renal Crônica, CKD-EPI). 


\section{Doença cardíaca coronariana (DCC)}

Os pacientes hipertensos com diabetes tipo 2 têm um risco 1,9 vez maior de apresentar doença cardiovascular do que os pacientes hipertensos sem diabetes (77). Considera-se que fatores como os níveis de fibrinogênio elevados, em particular durante o controle glicêmico deficiente, os níveis elevados do inibidor-1 do ativador de plasminogênio e o aumento da agregação plaquetária podem ser os responsáveis (78). Essas alterações relacionadas com o diabetes podem aumentar o risco de trombose no sítio de ruptura de uma placa e também o risco de reinfarto depois da terapia trombolítica ou da revascularização. Além disso, são frequentes as arritmias cardíacas como consequência da disfunção autonômica. A avaliação da DCC deve incluir uma prova de esforço seguido, se positivo, por um estudo de perfusão miocárdica (tomografia computadorizada por emissão de fóton único).

\section{Disfunção ventricular esquerda e insuficiência cardíaca}

O diabetes é um importante fator de risco para disfunção ventricular esquerda e insuficiência cardíaca. No estudo Monica Glasgow, a incidência de disfunção ventricular esquerda foi maior nos pacientes diabéticos (29\%) em comparação com os não diabéticos (7\%) (79). No estudo de Framingham, o risco relativo de insuficiência cardíaca clínica foi 3,8 vezes maior em homens diabéticos e 5,5 vezes nas mulheres com diabetes em comparação com aqueles sem diabetes (80). Nos pacientes diabéticos com hemoglobina glicosilada ( $\mathrm{HbAlc}$ ) menor que $7,0 \%$, a taxa de falha cardíaca foi 4,2 por 1.000 pacientes-ano, esta aumentando para 9,2 por 1.000 pacientes-ano quando a $\mathrm{HbAlc}$ foi maior que $10 \%$ (80). O mau prognóstico desses pacientes tem sido explicado por uma miocardiopatia diabética subjacente, agravada pela hipertensão e pela doença isquêmica do coração. (81).

A alta prevalência e as implicações na morbidade e na mortalidade que a insuficiência cardíaca traz determinam a imperiosa necessidade da identificação precoce de seus fatores de risco e dos sinais clínicos associados. Uma história clínica cuidadosa ajuda a detectar os sintomas da insuficiência cardíaca (dispneia aos esforços, ortopneia, tosse noturna e fatigabilidade fácil), embora pacientes com disfunção sistólica do ventrículo esquerdo possam não apresentar esses sintomas (82). Por isso, o diagnóstico da insuficiência cardíaca nos pacientes diabéticos e hipertensos pode requerer provas adicionais. Embora o eletrocardiograma e a radiografía do tórax possam ser úteis, a ecocardiografía com Doppler é necessária para visualizar as alterações cardíacas estruturais e funcionais que são subjacentes à insuficiência cardíaca, e é a prova recomendada quando se suspeita de insuficiência cardíaca. Como a insuficiência cardíaca é um preditor de morte cardíaca súbita, recomenda-se a realização de um ECG Holter para a detecção de arritmias.

\section{Acidente vascular encefálico}

As taxas de incapacidade relacionadas com AVE são mais altas nos diabéticos que nos não diabéticos (83). $\mathrm{O}$ risco de acidente cerebrovascular fatal versus não fatal parece ser maior quanto maior é o nível de HbAlC, inclusive muitos anos antes que o evento ocorra (83-85).

\section{TRATAMENTO DA HIPERTENSÃO ARTERIAL EM PACIENTES DIABÉTICOS}

\section{Tratamento não farmacológico da hipertensão arterial no diabetes melito}

\section{Plano dietético}

O consumo de hidratos de carbono deve representar $55-60 \%$ da ingestão total de calorias (ITC), minimizando os carboidratos simples refinados (açúcar, mel, fructose, melado etc.), ao mesmo tempo em que é recomendado aumentar os carboidratos complexos (verduras, frutas e grãos inteiros). $\mathrm{O}$ uso de adoçantes não calóricos é permitido, porém se deve selecionar os que têm baixo conteúdo de sódio.

O consumo de proteínas deve ser de $0,8-1 \mathrm{~g} / \mathrm{kg}$ de peso corporal ideal. As proteínas animais são preferidas devido ao seu alto valor biológico, porém os legumes e cereais devem ser incluídos para agregar a proteína da fibra. As fibras devem ser consumidas em uma quantidade aproximada de $30 \mathrm{~g} /$ dia, preferivelmente fibras solúveis.

O consumo de gordura não deve ser maior que 30\% da ITC, devendo ser 10\% saturada (graxa láctea e seus derivados), $10 \%$ poli-insaturada (óleos de origem vegetal, frutas secas, peixe) e 10\% monoinsaturadas (abacate, azeitonas, carne de porco, frango).

As recomendações para ingestão de vitaminas e oligoelementos são similares às que são feitas para a população em geral, de modo que o consumo de sódio deve 
ser de 3,2 g/dia (4-6 g de cloreto de sódio). Os alimentos muito processados devem ser evitados. É conveniente conhecer o conteúdo de sódio da água potável nas diferentes regiões da América Latina, uma vez que pode variar muito, como acontece nas águas engarrafadas. Deve-se realizar esforços para alcançar as recomendações no consumo de cálcio, sobretudo nas dietas hipocalóricas, por meio de uma escolha adequada dos alimentos. É necessário considerar as circunstâncias que podem interferir com a absorção de cálcio (síndrome de má-absorção, alimentos ricos em fito-hemaglutininas, drogas etc.). As necessidades de potássio normalmente se podem satisfazer mediante o aumento do consumo de verduras e frutas na dieta.

Em relação ao consumo de cafeína, não há evidências consistentes sobre os riscos e os benefícios do consumo crônico moderado de café ( 2 taças/dia). Já o consumo de álcool está diretamente relacionado com os níveis de PA e com a prevalência de hipertensão em diferentes populações. Também existem evidências de que o abuso de álcool bloqueia os efeitos dos fármacos anti-hipertensivos. Nos pacientes diabéticos, deve ser desestimulado o consumo de álcool ou permitir um consumo máximo de $30 \mathrm{~g} /$ dia para homens e $15 \mathrm{~g} /$ dia para as mulheres.

A distribuição dos alimentos deve ser feita em 3 ou 4 refeições e em 1 ou 2 lanches durante o dia. Dependendo dos horários que o paciente dispõe e do tratamento farmacológico do diabetes melito, igualmente se devem considerar as preferências étnicas, religiosas e o estado socioeconômico do paciente.

\section{Atividade física}

O estilo de vida sedentário e a falta de atividade física são fortes preditores de mortalidade cardiovascular, independente da presença de hipertensão e de outros fatores de risco. A intensidade do exercício recomendado deve ser individualizada de acordo com a condição clínica do paciente. $\mathrm{O}$ exame clínico é suficiente quando a atividade programada não supera $60 \%$ do consumo máximo de oxigênio $\left(\mathrm{VO}_{2}\right.$ máx, por exemplo, caminhar). Quando é prevista uma atividade mais intensa, é necessário um exame mais extenso das possibilidades de complicações do diabetes. Atenção especial deve ser prestada à doença cardíaca silenciosa (ou que está compensada), a retinopatia proliferativa, a nefropatia incipiente, a doença vascular periférica, a neuropatia periférica e autonômica, e osteoartropatia, especialmente das extremidades inferiores, já que o exercício pode contribuir para causar lesões nos pés. Um programa individualizado de três vezes por semana deve ser preparado, incluindo atividade aeróbica recreativa de intensidade moderada (equivalente a 3 a 5 METS) na forma de esportes ou exercícios em casa, que durem de 20 a 60 minutos por sessão, precedidos por 5 a 10 minutos de aquecimento, e seguidos por 5 a 10 minutos de relaxamento.

O paciente deve ser instruído sobre o uso de roupa apropriada para prevenir lesões dos pés, tais como meias de algodão e sapatos esportivos. A automonitorização da glicemia no sangue, antes e depois do exercício, pode auxiliar na prevenção de hipoglicemias e permitir ao paciente comprovar os efeitos benéficos do exercício sobre o controle glicêmico (86-88). O exercício intenso está contraindicado a pacientes com retinopatia proliferativa ativa e com manifestações clínicas de nefropatia e neuropatia.

\section{Tratamento farmacológico}

Os benefícios da redução da pressão arterial nos pacientes diabéticos foram demonstrados claramente nos estudos HOT (89) e UKPDS (90), entre outros (91-95). É necessário destacar que os pacientes diabéticos podem requerer um tratamento mais intenso para alcançar os mesmos níveis de PA que os não diabéticos. Na verdade, quase todos os pacientes diabéticos necessitam, além das medidas não farmacológicas, de um tratamento hipotensor combinado para alcançar os objetivos do tratamento, e tão logo quanto possível.

Recentemente tem sido muito debatida a meta da PAS que deve ser atingida para garantir uma proteção ótima do risco cardiovascular em pacientes hipertensos com diabetes. Uma série de diretrizes do passado $(1,2,69,70)$ havia recomendado uma meta menor $(<130 / 80 \mathrm{mmHg})$ em diabéticos e, em geral, em pacientes de alto risco) que a recomendada $(<140 / 90$ $\mathrm{mmHg}$ ) em pacientes hipertensos de risco baixo-moderado. No entanto, uma reavaliação recente das evidências disponíveis $(71,96)$ demonstrou que nenhum dos ensaios clínicos aleatórios de tratamento anti-hipertensivo em diabéticos com hipertensão levou a uma média de valores de PAS abaixo de $130 \mathrm{mmHg}$, e o estudo recente Action to Control Cardiovascular Risk in Diabetes (ACCORD) (97) não mostrou nenhuma redução adicional dos eventos cardiovasculares, e ainda foi observada uma maior incidência de efeitos adversos nos pacientes diabéticos aleatorizados para alcançar uma PAS $<120$ mmHg em comparação 
com aqueles aleatorizados para alcançar uma PAS < $140 \mathrm{mmHg}$ (os valores médios realmente alcançados foram de $119 \mathrm{mmHg}$ e $133 \mathrm{mmHg}$ ). Uma série de recentes metanálises $(98,99)$ dirigidas para correlacionar os eventos cardiovasculares com a PA obtida não encontrou nenhum benefício adicional ou piora na incidência de eventos cardiovasculares quando a pressão arterial alcançada era mais baixa, com a possível exceção da incidência de acidentes cerebrovasculares (99). $\mathrm{Na}$ realidade, parece que em pacientes hipertensos com diabetes o objetivo de PAS < $140 \mathrm{mmHg}$ deve ser recomendado assim como nos não diabéticos hipertensos. Os valores logo acima de $130 \mathrm{mmHg}$ [como ocorreu no ACCORD (97) e ADVANCE (100)] parecem ser seguros e podem ser mais eficazes na redução ou prevenção de microalbuminúria (100). Quanto ao objetivo da PAD, os resultados do $\operatorname{HOT}(89)$ e do UKPDS (90) indicam que os valores entre 80 e 85 $\mathrm{mmHg}$ são de benefício.

Enquanto aos pacientes diabéticos com nefropatia as diretrizes anteriores recomendaram como objetivo de pressão arterial cifras de $<130 / 80 \mathrm{mmHg}$ e $<$ $120 / 75 \mathrm{mmHg}$ em caso de proteinúria, uma revisão recente (101) demonstrou que essas recomendações não foram baseadas em resultados de ensaios clínicos de longo prazo e que foram obtidas de estudos observacionais não aleatórios. Assim, parece prudente, portanto, recomendar metas de pressão arterial idênticas para pacientes diabéticos com ou sem nefropatia.

Cinco classes de agentes anti-hipertensivos (diuréticos, betabloqueadores, inibidores da enzima conversora da angiotensina [IECA], bloqueadores dos receptores de angiotensina II [BRA] e bloqueadores de canais de cálcio [BCC]) têm sido utilizados nos ensaios clínicos aleatorizados, que demonstraram que reduzir a pressão arterial reduz significativamente os eventos cardiocerebrovasculares e a lesão renal em pacientes hipertensos com diabetes e sem diabetes (102). Em função disso, todos eles podem ser utilizados em pacientes hipertensos com diabetes tipo 2. Por outro lado, tem sido recomendado que, para iniciar o tratamento com monoterapia, se deve escolher os fármacos que bloqueiam o sistema renina-angiotensina-aldosterona (IECAs ou BRAs) devido ao seu maior efeito antiproteinúrico. Os BRAs são geralmente mais bem tolerados, o que é relevante em pacientes com hipertensão e diabetes, nos quais a adesão ao tratamento é essencial. Como regra geral, recomenda-se selecionar um agente de ação pro- longada que proporciona redução da pressão arterial durante 24 horas, com a finalidade de utilizar uma administração diária única. As agências reguladoras norte-americana e europeia (FDA e EMEA) aprovaram o ramipril (IECA) e o telmisartana (BRA) como fármacos cardioprotetores em pacientes com alto risco cardiovascular (pacientes hipertensos com diabetes tipo 2) com base nos resultados do estudo HOPE (94) e ONTARGET (103).

$\mathrm{Na}$ maioria dos pacientes hipertensos com diabetes tipo 2 , não é fácil alcançar as metas de pressão arterial com monoterapia e por isso frequentemente o tratamento inclui dois ou mais agentes anti-hipertensivos. Se antes de iniciar o tratamento as PAS/PAD estão muito acima dos valores objetivos, recomenda-se iniciar o tratamento com uma combinação de dois medicamentos, uma combinação fixa de um IECA ou BRA com um BCC di-hidropiridínico ou um diurético. O estudo The Avoiding Cardiovascular events through COMbination therapy in Patients Living with Systolic Hypertension (ACCOMPLISH) (104) demonstrou maiores benefícios com um IECA/CCB substituindo uma combinação IECA/diurético, porém esses dados interessantes necessitam ser confirmados. Quando se necessitam três medicamentos, recomenda-se utilizar um IECA ou um BRA mais um CCB e um diurético tiazídico. Nos pacientes com uma TFG $<30 \mathrm{ml} / \mathrm{min}$, os diuréticos tiazídicos devem ser substituídos por um diurético de alça (como furosemida), em doses apropriadas. A associação de um IECA e um BRA bem como a de um IECA ou BRA com um inibidor de renina (alisquireno) tem um grande efeito antiproteinúrico, mas a associação de um IECA e um BRA falhou em mostrar maior redução da pressão arterial no estudo ONTARGET (103) e na realidade mostrou mais efeitos adversos. Por outro lado, o estudo ALTITUDE (105), um ensaio que testou a associação de alisquireno com um IECA ou BRA, foi prematuramente interrompido por um maior número de eventos adversos da associação. Assim, a combinação de duas medicações diferentes que interferem com o sistema renina-angiotensina, em doses plenas, tem sido desencorajada.

Os diuréticos e os bloqueadores beta, particularmente em associação, aumentam a resistência à insulina e podem facilitar o aparecimento de diabetes em indivíduos predispostos, de modo que essa associação deve, se possível, ser evitada em pacientes hipertensos com pré-diabetes ou com síndrome metabólica. Recentemente, foi demonstrado que os bloqueadores betavasodilatadores, tais como o carvedilol e o nebivolol, não 
afetam a sensibilidade à insulina e, no caso do nebivolol, tem sido demonstrado que não altera a tolerância à glicose, até mesmo em associação com diuréticos tiazídicos (106). Portanto, os betabloqueadores vasodilatadores devem ser preferidos nas condições em que há razões para a administração de um bloqueador beta (doença isquêmica do coração, insuficiência cardíaca, taquiarritmia etc.).

Em doentes com insuficiência renal e/ou disfunção cardíaca, a função cardíaca pode melhorar pela administração de antagonistas dos receptores mineralocorticoides (espironolactona), que provaram ser eficazes no tratamento da hipertensão resistente. No entanto, os níveis séricos de potássio e TFG devem ser cuidadosamente monitorizados em pacientes com doença renal utilizando um inibidor do sistema BRA e um antagonista da aldosterona.

Tem sido demonstrado que os bloqueadores alfa melhoram a resistência à insulina e podem ser usados como agentes adicionais em doentes com hipertensão, diabetes tipo 2 , que não atingem as metas da pressão sanguínea, mas esses agentes não são recomendados como monoterapia exceto em pacientes hipertensos com hipertrofia prostática. A tabela 8 indica as drogas anti-hipertensivas que devem ser escolhidas para o tratamento farmacológico de pacientes hipertensos com diabetes tipo 2 e condições especiais.

\section{Populações especiais}

\section{Hipertensão e diabetes em afro-latino-americanos}

A população latino-americana é composta de diferentes grupos étnicos (107). Na América Latina, a prevalência de diferentes grupos étnicos em cada país é caracterizada, como em nenhum outro continente, por uma mistura de raças, etnias e culturas.

Apesar do grande número de pessoas negras na América Latina, não há nenhum estudo epidemiológico sobre a prevalência de hipertensão arterial e diabetes nessa população e nenhum estudo investigou, em uma amostra suficientemente grande e utilizando metodologias consistentes, a ingestão de alimentos, a atividade física e a composição corporal associada à hipertensão e ao diabetes. A maior parte das informações foi obtida com base em resultados de estudos realizados nos Estados Unidos que incluíram os negros que migraram da América Latina e do Caribe para os Estados Unidos $(108,109)$ ou jovens negros nascidos nos Estados Unidos, mas de origem latina ou do Caribe (32).
Portanto, a primeira recomendação do Consenso Latino-Americano é apelar para que as organizações acadêmicas e governamentais da América Latina apoiem investigações epidemiológicas, clínicas e terapêuticas em afrodescendentes na América Latina para ver se os resultados de estudos realizados nos Estados Unidos também se aplicam às pessoas negras que vivem na América Latina. No momento, há apenas um estudo que avaliou a importância da hipertensão arterial em um bairro rural de negros que viviam na província de Esmeraldas, no Equador (110), e que analisou 4.284 de 8.876 adultos que viviam na área: $1.542(36 \%)$ eram hipertensos, dos quais apenas quatro $(0,3 \%)$ estavam bem controlados com o tratamento. Nos 2,5 anos de acompanhamento, as doenças cardiovasculares foram as principais causas de morte na população adulta. Além disso, quatro em cada cinco pessoas que morreram de doenças cardiovasculares tinham um histórico de hipertensão. Com efeito, a prevalência de hipertensão não controlada neste estudo era muito maior do que a relatada em estudos realizados nos Estados Unidos.

Até que tenhamos uma quantidade adequada de dados provenientes de estudos a serem realizados na população negra da América Latina, o Consenso recomenda a adoção das orientações recentes da Sociedade Internacional de Hipertensão em negros (111). De acordo com este último documento, há uma clara diferença geográfica da prevalência da hipertensão entre os negros: 14\% na África Ocidental, 26\% no Caribe e 33\% nos Estados Unidos. Essas diferenças são atribuídas a diferenças na dieta e no estilo de vida. Nos Estados Unidos, as mulheres negras são mais sedentárias, consomem dietas altamente calóricas e são mais obesas desde o período pré-adulto $(112,113)$. Fatores genéticos e ambientais, tais como baixo nível socioeconômico, alta ingestão de sódio na dieta e/ou baixa ingestão de potássio e baixo peso ao nascer por desnutrição materna, têm sido associados com o desenvolvimento renal pobre e menor número de néfrons, o que predispõe à hipertensão e à disfunção renal precoce (114,115).

As complicações cardiorrenais associadas à hipertensão e ao diabetes tipo 2 (hipertrofia do ventrículo esquerdo do coração, insuficiência cardíaca crônica em fase terminal, acidente vascular cerebral, ou insuficiência renal crônica em fase final) ocorrem com mais frequência em negros do que em brancos. Negros hipertensos têm um risco 4-20 vezes maior de progressão para diálise do que brancos com níveis 
semelhantes de pressão arterial, e a mortalidade em homens afro-americanos é três vezes maior (49\%) do que em brancos não hispânicos nos Estados Unidos (16\%), e duas vezes e meia maior em mulheres negras (37\%) do que nas mulheres brancas não hispânicas (14\%) (116).

A escolha entre a monoterapia ou terapia de combinação anti-hipertensiva depende da presença ou ausência de comorbidades e eficácia específica dos medicamentos a serem utilizados. Estudos comparativos demonstraram que os doentes hipertensos de raça negra têm uma melhor resposta aos diuréticos tiazídicos (hidroclorotiazida ou clortalidona) e bloqueadores dos canais de cálcio que os inibidores da ECA ou BRA, e aos bloqueadores beta $(117,118)$. O melhor controle é sempre obtido pela redução da ingestão de sódio. Além disso, os negros são mais propensos a ter o edema angioneurótico em resposta aos inibidores da ECA do que os brancos (119). Portanto, nos negros, a monoterapia deve basear-se em um diurético ou um bloqueador dos canais de cálcio e, quando for necessária terapêutica combinada, deve-se incluir uma CBC e/ ou um diurético mais um bloqueador sistema RAA, de preferência, um BRA.

\section{Hipertensão e diabetes na população andina}

A população da América Latina que vive na Cordilheira dos Andes comparte características semelhantes, e padrões históricos de colonização, com aqueles que vivem em altitudes mais baixas, sendo em sua maioria indígena ou mestiça. As pessoas que vivem em altitudes elevadas (mais de 3.000 metros acima do nível do mar) são um grupo especial, no qual a prevalência de hipertensão e diabetes é bem conhecida. Um estudo da população (120), que incluiu 1.878 adultos nos Andes peruanos, mostrou que a prevalência de hipertensão foi de $15,7 \%$ (intervalo de confiança [IC] de 95\%: 14,0$17,4 \%)$, não havendo diferenças de sexo, mas aumento significativo com a idade, particularmente nas mulheres. As taxas de conhecimento, tratamento e controle foram $47,9 \%, 39,5 \%$ e 14\%, respectivamente. A pressão arterial diastólica aumentou até a idade de 50 e depois estabilizou, enquanto a pressão arterial média continuou a aumentar com a idade, até os 50 anos. O tipo predominante de alteração foi a hipertensão arterial sistólica, diastólica $(41,7 \%, 95 \%, 35,1-48,5 \%)$ ou isolada diastólica. A hipertensão sistólica isolada representou apenas $29,3 \%$ dos casos (95\% IC, 23,9-35,4\%) e foi res- ponsável por uma minoria de casos em todas as faixas etárias antes dos 70 anos. $\mathrm{O}$ fato de que a hipertensão diastólica é predominante na Cordilheira dos Andes, mais de 3.000 metros acima do nível do mar, foi recentemente confirmada em outro estudo (121), que constatou que mais de $50 \%$ da população não sabia do seu estado hipertensivo. Esse estudo também mostrou que a prevalência de hipertensão foi semelhante na costa, serra e selva do Peru $(120,121)$.

\section{Hipertensão e diabetes em idosos}

O relatório demográfico da Organização Pan-Americana da Saúde (OPAS)/OMS, na América Latina (122), mostra que a população acima de 60 anos representa $14 \%$ do total da população na Argentina, 10\% no Brasil, 13\% no Chile, $8 \%$ na Colômbia, 9\% no Equador, 7\% no Paraguai, de $8 \%$ no Peru, $18 \%$ no Uruguai, $8 \%$ na Venezuela e $8 \%$ no México. Os idosos, definidos como aqueles com mais de 65 anos, têm um maior risco de hipertensão arterial, hipertensão sistólica isolada especialmente $(123,124)$, o que implica risco cardiovascular adicional, como pressão de pulso maior que $65 \mathrm{mmHg}$, a qual está associada com aumento da rigidez da parede das grandes artérias e aumento da morbidade e mortalidade (124) cardiovascular. O MAPA de 24 horas é considerado uma ferramenta útil para otimizar a avaliação clínica de idosos hipertensos $(125,126)$. Neles há uma queda anormal da pressão arterial noturna e ondas de aumento pela manhã, o que está associado com aumento do risco de doença cerebrovascular $(127,128)$, embora esses achados recentemente têm sido questionados (129).

Todos os ensaios clínicos que têm demonstrado os benefícios da BP baixando em idosos têm levado a uma meta de PAS < $150 \mathrm{mmHg}$ (96), e isso deve ser considerado o alvo baseado em evidências objetivas para idosos hipertensos, mas idosos saudáveis por meio de um objetivo semelhante recomendam a proposta para jovens hipertensos $(\leq 140 \mathrm{mmHg})$. Existe também evidência de benefícios na redução de PAS $<150 \mathrm{mmHg}$ em pacientes hipertensos com mais de 80 anos (130). As pessoas frágeis ou complicadas devem ser tratadas com cuidado especial para não piorar suas condições gerais de saúde.

Em pessoas idosas, o tratamento farmacológico deve ser iniciado gradualmente para assegurar a boa tolerabilidade e qualidade de vida. A sexualidade (disfunção sexual), o sono e o estado funcional devem ser considerados na avaliação clínica dessa população (10). 
Diversos ensaios clínicos demonstraram os benefícios da redução da hipertensão sistólica isolada (131133) pelo uso de diuréticos ou BCCs. Outros ensaios clínicos, em idosos hipertensos, incluíram um número significativo de pacientes com hipertensão sistólica isolada: foram utilizados inibidores de ECA e BRAs, e também foi mostrado que essas drogas são úteis nesses pacientes, tanto em monoterapia como em combinação.

Nos doentes com risco cardiovascular ou comorbidades, a droga mais adequada deve ser selecionada de acordo com doenças concomitantes, como indicado na tabela 8. São recomendados medicamentos de ação prolongada para melhor adesão, bem como ação anti-hipertensiva prolongada de 24 horas.

Tabela 8. Recomendações de outros medicamentos para os pacientes hipertensos com diabetes tipo 2 nas condições especiais

\begin{tabular}{|c|c|}
\hline $\begin{array}{l}\text { Doença cardíaca coronária e/ou } \\
\text { disfunção ventricular esquerda }\end{array}$ & $\begin{array}{l}\text { IECA/BRA, betabloqueadores, } \\
\text { antagonistas da aldosterona }\end{array}$ \\
\hline $\begin{array}{l}\text { Hipertensão sistólica isolada nos } \\
\text { idosos }\end{array}$ & $\begin{array}{l}\text { Bloqueadores dos canais de cálcio, } \\
\text { bloqueadores beta, diuréticos, BRA }\end{array}$ \\
\hline Angina pectoris & $\begin{array}{l}\text { Bloqueadores dos canais de cálcio, } \\
\text { betabloqueadores, frequentemente } \\
\text { associados }\end{array}$ \\
\hline Insuficiência renal crônica & $\begin{array}{l}\text { IECA ou BRA, sobretudo na presença de } \\
\text { microalbuminúria ou proteinúria franca }\end{array}$ \\
\hline Doença arterial periférica & Bloqueadores dos canais de cálcio \\
\hline Pacientes com fibrilação auricular & $\begin{array}{l}\text { Bloqueadores beta, BRA, IECA, } \\
\text { bloqueadores dos canais de cálcio não } \\
\text { di-hidropiridínicos }\end{array}$ \\
\hline Hipertrofia ventricular esquerda & IECA, BRA, BCC \\
\hline Hipertrofia prostática benigna & Bloqueadores alfa \\
\hline
\end{tabular}

IECAs: inibidores da enzima de conversão da angiotensina; BRAs: bloqueadores do receptor da angiotensina; BCC: bloqueadores dos canais de cálcio.

\section{O PAPEL DO MEIO AMBIENTE E DA EPIGENÉTICA NA SÍNDROME METABÓLICA, HIPERTENSÃO E DIABETES NA AMÉRICA LATINA}

O aumento da incidência de síndrome metabólica, diabetes tipo 2 e doenças cardiovasculares na América Latina parece estar associado a influências ambientais e características étnicas da população (134). Isso levanta a possibilidade de que a predisposição genética de determinados grupos étnicos pode interagir com fatores ambientais, o que poderia explicar diferenças na incidência da doença. Recentemente, há um considerável interesse na influência particular de exposição ambiental durante a vida uterina e da vida pós-natal precoce. A proposta baseia-se na hipótese de Origens Evolutivas da Doença, que enfatiza que condições ambientais têm influência durante períodos críticos do início da vida, nos quais a estrutura corporal e a função do corpo são definidas para a vida. Mais recentemente, os primeiros efeitos do ambiente têm sido concebidos em termos de epigenética.

Epigenética é a ciência que explica a variação na expressão de genes em resposta a alterações das condições ambientais. Esse termo inclui qualquer processo que altera a atividade do gene, sem alterar a sequência de DNA, levando a alterações rápidas e reversíveis de DNA (por exemplo, metilação) ou cromatina, que podem ser transmitidas para as células-filhas. A metilação do DNA de uma região reguladora de um gene específico pode inibir a expressão genética. A cromatina é o complexo nuclear que consiste em DNA envolvido em torno de proteínas com histonas, as quais podem ser modificadas por acetilação e influenciar a expressão de genes (135).

Os mecanismos que controlam processos epigenéticos ainda não são completamente compreendidos, mas está claro que as variações de DNA herdadas poderiam alterar a sensibilidade a certos desencadeadores ambientais ou alterar a natureza da resposta epigenética a uma determinada exposição. No contexto latino-americano, a questão é o que explicaria a diversidade da síndrome metabólica: se diferenças na suscetibilidade para o desenvolvimento de níveis variados de gordura visceral são dependentes de variações regionais e étnicas em processos epigenéticos ou simplesmente se devem a diferenças na exposição ambiental.

É sabido que na América Latina desnutrição materna e desnutrição infantil são um grande problema a ser resolvido em uma proporção significativa das populações pobres (136). Além disso, na América Latina, encontra-se uma alta prevalência de hipertensão arterial em crianças, adolescentes e adultos com crescimento interrompido por má nutrição (137-144). Um estudo realizado no Brasil (137), que investigou o comportamento da pressão arterial em uma amostra aleatória de adolescentes com atraso no crescimento (10-16A, $\mathrm{n}=$ $56)$, que vivem em favelas, mostrou um elevado percentual de pessoas com uma pressão acima do percentil 90 e 95, após o ajuste para altura e estavam em maior risco de desenvolver hipertensão. Considerando o grupo de pacientes como um todo, a prevalência de hipertensão arterial diastólica foi de 21\% (IC 95\%, 10-32\%). A prevalência de casos com pressão arterial sistólica ou diastólica acima do percentil 90 foi de 51\% (IC 95\%, $37-65 \%)$. Outro estudo no nordeste do Brasil (138) em 
416 adultos (18-60 anos), também moradores de um bairro pobre, mostrou que a prevalência de hipertensão foi de $28,5 \%$ (mulheres $=38,5 \%$, homens $=18,4 \%$ ). A pressão arterial sistólica e diastólica aumentou paralelamente com a diminuição da altura, e a hipertensão arterial foi mais frequente em mulheres que eram obesas e de baixa altura (50\%) comparada com aqueles que eram obesos, mas não tinham estatura baixa (OR 1,98, IC 95\%, 1,22-2,96). Recentemente, outro estudo (139) investigou as condições de saúde de mães que tiveram uma baixa estatura em comparação com mulheres sem desnutrição, ou seus filhos: a baixa estatura materna foi independentemente associada com obesidade, obesidade abdominal e pressão arterial elevada. Além disso, a baixa estatura materna foi associada com baixo peso e retardo de crescimento em crianças nascidas dessas mães. Na Colômbia, foi mostrado que a pressão arterial de crianças de até 11 anos de idade que tinham um IMC médio de 21, o maior tercil, mostrou um aumento de $10 \mathrm{mmHg}$ em relação às crianças com um IMC médio de 15, o menor tercil (140). Franco e cols., no Brasil, (141) relataram alterações no sistema simpático-adrenal e renina-angiotensina, em recém-nascidos pequenos para a idade gestacional. Eles investigaram os níveis plasmáticos da enzima conversora de angiotensina (ACE), a angiotensina e catecolaminas em crianças de 8-13 anos de idade, para determinar possível correlação entre os níveis plasmáticos, peso ao nascer e pressão arterial. Os níveis circulantes de norepinefrina foram significativamente maiores em meninas pequenas para a idade gestacional em comparação com meninas que nasceram com um peso adequado para a idade gestacional. Além disso, a angiotensina II e a atividade da ECA foram maiores em crianças pequenas para a idade gestacional. Por outro lado, houve uma associação significativa entre os níveis circulantes de angiotensina II e a atividade da ECA e a PAS. Outro estudo realizado no Brasil (142) mostrou que a atividade da ECA aumenta com a elevação da pressão arterial sistólica e diastólica em crianças com retardo de crescimento, independente do peso ao nascer.

Embora na América Latina a prevalência de diabetes melito tipo 2 em indivíduos com baixo peso e desnutrição em seus primeiros anos de vida não é conhecida, sabe-se que os países pobres com rápida urbanização são particularmente vulneráveis para apresentar DM2 e têm experimentado um aumento significativo na prevalência da diabetes (143). Alterações prejudiciais ao metabolismo da glicose em crianças mexicanas que so- freram de desnutrição na infầncia foram relatadas em um estudo. No mesmo, foram examinados os efeitos da desnutrição sobre a tolerância à glicose e insulina no plasma, no primeiro ano de vida, e se descobriu que a desnutrição em vida extrauterina precoce, independentemente do peso de nascimento, está associada com hiperinsulinemia e redução da sensibilidade à insulina. Os mesmos parâmetros pioraram com o IMC aumentando na vida adulta (143).

$\mathrm{Na}$ verdade, é interessante especular que o aumento da prevalência de hipertensão, síndrome metabólica e diabetes tipo 2 observado atualmente na América Latina seja o resultado da discrepância entre o ambiente nutricional durante a vida fetal e a primeira infância e o ambiente nutricional e estilo de vida na fase adulta. Essa discrepância causa confusão entre a programação fetal inicial, e as circunstâncias adultas criadas pela imposição de novos estilos de vida (144). O conflito de programação inicial do feto e a presença de obesidade abdominal final poderiam resultar em maior sensibilidade da nossa população de desenvolver um estado de inflamação sistêmica, resistência à insulina e, consequentemente, uma epidemia de hipertensão, síndrome metabólica e diabetes. Os papéis relativos desempenhados por fatores genéticos e ambientais e da interação entre os dois ainda é um assunto de grande debate que merece investigação futura.

A recomendação do Consenso da América Latina é a de que, nos ambientes acadêmicos, sejam realizadas pesquisas que visem estabelecer os mecanismos epigenéticos que poderiam explicar a relação entre desnutrição materna, restrição de crescimento inicial e posterior desenvolvimento de obesidade abdominal e doença cardiovascular na América Latina.

\section{AGRADECIMENTOS}

Participantes do Consenso

Diretores: LÓPEZ-JARAMILLO, Patricio (Colômbia); SÁNCHEZ, Ramiro (Argentina).

Coordenadores: RAMÍREZ, Agustín J. (Argentina); SCHMID, Helena (Brasil).

Assessores: ZANCHETTI, Alberto (Itália); HARRAP, Stephen (Austrália).

Participantes:

ACCINI, Jose Luis (Colômbia)

ALVERNIA, Sergio (Colômbia)

ARCOS, Edgar (Colômbia)

AYALA, Myrian (Paraguai)

BENDERSKY, Mario (Argentina)

BOLÍVAR, Fabio (Colômbia)

BOTERO, Rodrigo (Colômbia) 
BRYCE, Alfonso (Peru)

BUELVAS, Janes (Colômbia)

CALDERÓN, Carlos (Colômbia)

CÁRDENAS, Juan Mauricio (Colômbia)

CASANOVA, María Eugenia (Colômbia)

CASTILLO, Gilberto (Colômbia)

COBOS, Leonardo (Chile)

CURE, Carlos (Colômbia)

DÍAZ, Margarita (Uruguai)

DUARTE, Yan Carlos (Equador)

DUPERLY, John (Colômbia)

ECHEVERRÍA, Luis (Colômbia)

ESPINOSA, Tatiana (Colômbia)

FELICIANO, John (Colômbia)

FOSS, Milton C. (Brasil)

FREIRE, Peggy (Equador)

GARCÍA, Henry (Colômbia)

GARCÍA, Luis Hernando (Colômbia)

GARCÍA, Santiago (Equador)

GÓMEZ-ARBELÁEZ, Diego (Colômbia)

HERNÁNDEZ, Erick (Colômbia)

HIGUERA, Juan D. (Colômbia)

HUERTAS, Diego (Colômbia)

JARAMILLO, Sergio (Colômbia)

JÁUREGUI, Isabel (Colômbia)

LANAS, Fernando (Chile)

LARA, Joffre (Equador)

LIZCANO, Fernando (Colômbia)

MACHADO, Livia (Venezuela)

MANRIQUE, Helard (Peru)

MANZUR, Fernando (Colômbia)

MÁRQUEZ, Álvaro (Colômbia)

MÁRQUEZ, Gustavo (Colômbia)

MARTÍNEZ, Javier (Colômbia)

MARTÍNEZ, Luz X. (Colômbia)

MEDINA, Félix (Peru)

MEDINA, Roberto (México)

MELGAREJO, Enrique (Colômbia)

MERCHÁN, Alonso (Colômbia)

MIRANDA, Harold (Colômbia)

MOLINA, Dora I. (Colômbia)

NAVARRETE, Solón (Colômbia)

PARRA, Gustavo (Colômbia)

PARRA CARRILLO, José Z. (México)

PASQUEL, Miguel (Equador)

PEÑA, Jesús Alirio (Colômbia)

PEÑAHERRERA, Ernesto (Equador)

PEREZ, Maritza (Colômbia)

PINEDA, Belkis (Colômbia)

PISKORZ, Daniel (Argentina)

PONTE, Carlos (Venezuela)

PRAT, Hernán (Chile)

REY, Juan José (Colômbia)

RODRIGUEZ, Jesús (Colômbia)

RODRIGUEZ, Patricia (Colômbia)

SÁNCHEZ, Gregorio (Colômbia)

SIERRA, Iván D. (Colômbia)

SOTOMAYOR, Arístides (Colômbia)

SYNAY, Isaac (Argentina)

URIBE, Juan Carlos (Colômbia)

URINA, Manuel (Colômbia)

VARGAS, Ricardo (Chile)
VESGA, Boris (Colômbia)

VELANDIA, Carlos (Colômbia)

VILLAR, Raúl (Chile)

VILLARREAL, Eduardo (Colômbia)

YENES, Alejandro (Chile)

Declaração: os autores declaram não haver conflitos de interesse científico neste estudo.

\section{REFERÊNCIAS}

1. World Health Organization, International Society of Hypertension Writing Group. 2003 World Health Organization (WHO)/International Society of Hypertension (ISH) statement on management of hypertension. J Hypertens. 2003;21:1983-92.

2. European Society of Hypertension-European Society of Cardiology Guidelines Committee. 2003 European Society of Hypertension-European Society of Cardiology guidelines for the management of arterial hypertension. J Hypertens. 2003;21:1011-53.

3. Delamothe T. Wanted: guidelines that doctors will follow. BMJ. 1993;307(6898):218.

4. McColl A, Smith H, White P, Field J. General practitioners' perceptions of the route to evidence based medicine: a questionnaire survey. BMJ. 1998;316:361-5.

5. Woolf SH. Practice guidelines, a new reality in medicine. II. Methods of developing guidelines. Arch Intern Med. 1992;152:946-52.

6. Cabana MD, Rand CS, Powe NR, Wu AW, Wilson MH, Abboud PA, et al. Why don't physicians follow clinical practice guidelines? A framework for improvement. JAMA. 1999;282(15):1458-65.

7. World Health Organization. Preventing chronic diseases: a vital investment: WHO global report. Geneva: World Health Organization; 2005. Page 1-13. [citado 2012 Set 10]. Disponível em: http:// www.who.int/chp/chronic_disease_report/en/

8. Organización Panamericana de la Salud. Las Américas: una población creciente urbana que está envejeciendo. Washington: OPS; 2002. [citado 2012 Set 10]. Disponível em: http://www.paho. org/Spanish/DBI/MDS/Press1_SEA_2002.htm

9. Organización Panamericana de la Salud. Salud en las Américas 2007. Washington: OPS; 2007. [citado 2012 Set 10]. Disponível em: http://www.paho.org/hia/home.html

10. Sánchez RA, Ayala M, Baglivo H, Velázquez $C$, Burlando G, Kolmann $O$, et al.; on behalf of the Latin American expert Group. Latin American guidelines on Hypertension. J Hypertens. 2009;27:905-22.

11. Ezzati M, Lopez AD, Rodgers A, Van der Hoorn S, Murray CJ; Comparative Risk Assessment Collaborating Group. Selected major risk factors and global and regional burden of disease. Lancet. 2002;360:1347-60.

12. Schargrodsky $H$, Hernández-Hernández $R$, Champagne BM, Silva $H$, Vinueza R, Silva-Ayçaguer LC, et al. for the CARMELA study. CARMELA: assessment of the CV risk in seven Latin American cities. Am J Med. 2008;121:58-65.

13. Barreto S, Azeredo V, Oliveira J, Guerra H, Guati-Mosim P, Furtado $M$. Hypertension and clustering of cardiovascular risk factors in a community in southeast Brazil. The Bambui Health and Ageing Study. Arq Bras Cardiol. 2001;77:576-81.

14. Jiménez J, Palacios $M$, Cañete $F$, Barriocanal L, Medina $U$, Figueredo $R$, et al. Prevalence of diabetes mellitus and associated cardiovascular risk factors in an adult urban population in Paraguay. Diabetic Medicine. 1998;15:334-8.

15. Fasce E, Campos I, Ibañez P, Flores M, Zarate H, Román O, et al.Trends in prevalence, awareness, treatment and control of hypertension in urban communities in Chile. J Hypertens. 2007;25:1807-11. 
16. Guerrero-Romero F, Rodríguez M. Prevalencia de hipertensión arterial y factores asociados en la población rural marginada. Salud Pública México. 1998;40:339-46.

17. Teo K, Chow CK, Vaz M, Ranjarajan S, Yusuf S; PURE Investigators-Writing Group. The Prospective Urban Rural Epidemiology (PURE) study: examining the impact of societal influences on chronic non-communicable diseases in low-, middle-, and high-income countries. Am Heart J. 2009;158:1-7.

18. Sempértegui F, Estrella B, Tucker KL, Hamer DH, Narvaez X, Sempértegui $M$, et al. Metabolic syndrome in the elderly living in marginal peri-urban communities in Quito, Ecuador. Public Health Nutr. 2011;14:758-67.

19. Alvarez C, Salazar R, Galindez J, Rangel F, Castañeda ML, Lopardo $G$, et al. Metabolic syndrome in HIV-infected patients receiving antiretroviral therapy in Latin America. Braz J Infect Dis. 2010;14:256-63.

20. Bermúdez V, Marcano RP, Cano C, Arráiz N, Amell A, Cabrera M, et al. The Maracaibo city metabolic syndrome prevalence study: design and scope. Am JTher. 2010;17:288-94.

21. Escobedo J, Schargrodsky H, Champagne B, Silva H, Boissonnet $C P$, Vinueza $R$, et al. Prevalence of the metabolic syndrome in Latin America and its association with sub-clinical carotid atherosclerosis: the CARMELA cross sectional study. Cardiovasc Diabetol. 2009; 6:8-52.

22. Caceres M, Teran CG, Rodriguez S, Medina M. Prevalence of insulin resistance and its association with metabolic syndrome criteria among Bolivian children and adolescents with obesity. BMC Pediatr. 2008;8:31.

23. Royer M, Castelo-Branco C, Blümel JE, Chedraui PA, Danckers L, Bencosme A, et al.; Collaborative Group for Research of the Climacteric in Latin America. The USA National Cholesterol Education Programme Adult Treatment Panel III (NCEP ATP III): prevalence of the metabolic syndrome in postmenopausal Latin American women. Climacteric. 2007;10:164-70.

24. Bustos $P$, da Silva AA, Amigo $H$, Bettiol $H$, Barbieri MA. Metabolic syndrome in young adults from two socio-economic Latin American settings. Nutr Metab Cardiovasc Dis. 2007;17:581-9.

25. Rueda-Clausen C, Silva F, López-Jaramillo P. Epidemic of obesity and overweigh in Latin America and the Caribbean. Int J Cardiol. 2008;123:111-2.

26. Garcia RG, Pérez M, Maas R, Schwedhelm E, Böger RH, López-Jaramillo P. Plasma concentrations of asymmetric dimethylarginine (ADMA) in metabolic syndrome. Int J Cardiol. 2007;122:176-8.

27. López-Jaramillo P, Rueda-Clausen C, Silva FA. The utility of different definitions of metabolic syndrome in Andean population. Int J Cardiol. 2007;116:421-2.

28. Garcia RG, Cifuentes AE, Caballero RS, Sánchez L, López-Jaramillo $P$. A proposal for an appropriate central obesity diagnosis in Latin American population. Int J Cardiol. 2005;110:263-4.

29. Pérez M, Casas JP, Cubillos LA, Serrano NC, Silva FA, Morillo CA, et al. Using waist circumference as screening tool to identify Colombian subjects at cardiovascular risk. Eur J Cardiovasc Preven and Rehab. 2003;10:328-35.

30. Pinzón JB, Serrano NC, Díaz LA, Mantilla G, Velasco HM, Martínez LX, et al. Impacto de las nuevas definiciones en la prevalencia de síndrome metabólico en una población de Bucaramanga, Colombia. Biomédica. 2007;27:172-9.

31. Piegas LS, Avenzum A, Pereira JC, Neto JM, Hoepfner C, Farran $\mathrm{JA}$, et al. Risk factors for myocardial infarction in Brazil. Am Heart J. 2003;146:331-8.

32. Messiah SE, Carrillo-Iregui A, Garibay-Nieto N, López-Mitnik G, Cossio S, Arheart KL. Prevalence of metabolic syndrome in US-born Latin and Caribbean youth. J Immigr Minor Health. 2009;11:366-71.
33. Velásquez-Meléndez G, Kac G, Valente JG, Tavares R, Silva CQ, Garcia ES. Evaluation of waist circumference to predict general obesity and arterial hypertension in women in Greater Metropolitan Belo Horizonte, Brazil. Cad Saude Publica. 2002;18:765-71.

34. Berber A, Gómez Santos R, Fanghanel G, Sanchez- Reyes L. Anthropometric indexes in the prediction of type 2 diabetes mellitus, hypertension and dyslipidaemia in a Mexican population. Int J Obes Relat Metab Disord. 2001;25:1794-9.

35. Kabagambe EK, Baylin A, Campos H. Non-fatal acute myocardial infarction in Costa Rica: Modifiable risk factors, population attributable risk, and adherence to dietary guidelines. Circulation. 2007;115:1075-81.

36. Manzur F, Alvear C, Alayón A. Caracterización fenotípica y metabólica del síndrome metabólico en Cartagena de Indias. Rev Colomb Cardiol. 2008;15:97-101.

37. Sánchez F, Jaramillo N, Vanegas A, Echeverría JG, León AC, Echeverría $E$, et al. Prevalencia y comportamiento de los factores de riesgo del síndrome metabólico según los diferentes intervalos de edad, en una población femenina del área de influencia de la Clínica Las Américas, en Medellín-Colombia. Rev Colomb Cardiol. 2008;15:102-10.

38. Villegas A, Botero J, Arango I, Arias S, Toro M. Prevalencia del síndrome metabólico en El Retiro, Antioquia, Colombia. latreia 2003;16:291-7.

39. Merchán A. Síndrome metabólico y riesgo de enfermedad cardiovascular. Acta Med Colomb. 2005;30:150-4.

40. Lombo B, Villalobos C,Tique C, Satizábal C, Franco C. Prevalencia del síndrome metabólico entre los pacientes que asisten al servicio de la clínica de hipertensión de la Fundación Santa Fe de Bogotá. Rev Colomb Cardiol. 2006;12:472-8.

41. Aschner P. Síndrome metabólico en una población rural y una población urbana de la región andina colombiana. Rev Med. 2007;15:154-62.

42. Márquez-Sandoval F, Macedo-Ojeda G, Viramontes-Hörner D, Fernández-Ballart JD, Salas Salvadó J, Vizmanos B. The prevalence of metabolic syndrome in Latin America: a systematic review. Public Health Nutr. 2011;14:1702-13.

43. Guerrero-Romero F, Rodríguez M, Sandoval F, Alvarado R. Prevalence of hypertension in indigenous inhabitants of traditional communities from north of Mexico. J Hum Hypertens. 2000;14:555-9.

44. Sichieri R. Dietary patterns and their association with obesity in the Brazilian city of Rio de Janeiro. Obes Res. 2002;10:42-8.

45. Arroyo P, Loria A, Fernandez V, Flegal KM, Kuri P. Prevalence of pre-obesity in urban adult Mexicans in comparison with other large surveys. Obes Res. 2000;8:179-85.

46. Sereday M, Gonzalez C, Giorgini P, De Loredo L, Braguinsky J, Cobeñas $C$, et al. Prevalence of diabetes and obesity in the central area of Argentina. Diabetes Metab. 2003;29:5S28-43.

47. Wilks R, Rotimit $C$, Bennet F, McFarlane-Anderson N, Kaufmant JS, Anderson SG, et al. Diabetes in the Caribbean: results of a population survey from Spanish Town, Jamaica. Diab Med. 1999;16:875-83.

48. Piskorz D. Factores de riesgo en la ciudad de Rosario. Resultados del Estudio FAROS. Revista de la Federación Argentina de Cardiología. 1999;64:245-51.

49. Avila Curiel A, Shamah-Levy T, Chávez-Villasana A, Galindo Gómez C. Encuesta urbana de alimentación y nutrición en la zona metropolitana de la ciudad de México 2002. México DF: Instituto Nacional de Ciencias Médicas y Nutrición Salvador Zubirán, Instituto Nacional de Salud Pública, 2003.

50. De Onis M, Blössnner M. Prevalence and trends of overweight among preschool children in developing countries. Am J Clin Nutr. 2000;72:1032-9.

51. Martorell R, Kettel Khan L, Hughes M, Grummer-Strawn. Obesity in Latin American women and children. J Nut. 1998;128:1464-73. 
52. Monteiro CA. Epidemiologia da obesidade. In: Halpern A, Matos AFG, Suplicy H, Mancini MC, Zanella MT (eds). Obesidade. São Paulo: Editorial Lemos; 1998; p. 15-30.

53. Pisabarro R, Gutiérrez M, Bermúdez $C$, Préndez D, Recalde A, ChaftareY, et al. Segunda encuesta nacional de sobrepeso y obesidad (ENSO 2) en adultos. Rev Med Urug. 2009;25:14-26.

54. Orduñez P, Espinosa A, Cooper R, Kaufman J, Nieto F. Hypertension in Cuba: evidence of narrow black-white difference. J Hum Hypertens. 1998;12:111-6.

55. Magalhães N, Pozzan R, Brandão AA, Cerqueira R, Rousoulieres A, Szwarcwald C, et al. Early blood pressure level as a mark of familial aggregation of metabolic cardiovascular risk factors. The Rio de Janeiro Study. J Hypertens. 1998;6:1885-9.

56. Díaz ME. Hypertension and obesity. J Hum Hypertens. 2002;16 (Suppl 1):S18-22.

57. Filozof C, Gonzalez C, Sereday M, Mazza C, Braguinsky J. Obesity prevalence and trends in Latin American countries. Obes Rev. 2001;2:99-106.

58. Samper-Ternent R, Michaels-Obregon A, Wong R. Coexistence of obesity and anemia in older Mexican adults. Ageing Int. 2011;37:104-17.

59. Monteiro CA, Moura EC, Conde WL, Popkin BM. Socioeconomic status and obesity in adult populations of developing countries: a review. Bull World Health Organ. 2004;82:940-6.

60. Monteiro CA, Conde WL, Lu B, Popkin BM. Obesity and inequities in health in the developing world. Int $\mathrm{J}$ Obes Relat Metab Disord. 2004;28:1181-6.

61. Williams K, Stern MP, Gonzalez-Villalpando C. Secular trends in obesity in Mexico City and in San Antonio. Nutr Rev. 2004;62:S158-62.

62. Alberti KG, Eckel RH, Grundy SM, Zimmet PZ, Cleeman JI, Donato $K A$, et al. Harmonizing the metabolic syndrome. A Joint Interim Statement of the International Diabetes Federation Task Force on Epidemiology and Prevention; National Heart, Lung, and Blood Institute; American Heart Association; World Heart Federation; International Atherosclerosis Society; and International Association for the Study of Obesity. Circulation. 2009;120:1640-5.

63. Reaven GM. Insulin resistance/compensatory hyperinsulinemia, essential hypertension, and cardiovascular disease. J Clin Endocrinol Metab. 2003;88:2399-403.

64. Aschner P, Buendía R, Brajkovich I, Gonzalez A, Figueredo R, Juarez $X E$, et al. Determination of the cut-off point for waist circumference that establishes the presence of abdominal obesity in Latin American men and women. Diabetes Res Clin Pract. 2011;93:243-7.

65. American Diabetes Association. Executive summary: standards of medical care in diabetes. 2010. Diabetes Care. 2010;33(Suppl 1):S4-10.

66. Schriger DL, Lorber B. Lowering the cut point for impaired fasting glucose: where is the evidence? Where is the logic? Diabetes Care. 2004;27:592-601.

67. Rutter MK, Nesto RW. Blood pressure, lipids and glucose in type 2 diabetes: how low should we go? Re-discovering personalized care. Eur Heart J. 2011;32:2247-55.

68. Jonsson B. Revealing the cost of type II diabetes in Europe. Diabetologia. 2002;45:S5-12.

69. Chobanian AV, Bakris GL, Black HR, Cushman WC, Green LA, Izzo $\mathrm{JL} J$ r, et al. The Seventh Report of the Joint National Committee on Prevention, Detection, Evaluation, and Treatment of High Blood Pressure. The JNC 7 report. JAMA. 2003;289:2560-72.

70. Mancia G, De Backer G, Dominiczak A, Cifkova R, Fagard R, Germano G, et al. 2007 ESH-ESC Practice Guidelines for the Management of Arterial Hypertension: ESH-ESCTask Force on the Management of Arterial Hypertension. J Hypertens. 2007;25:1105-87.
71. Mancia G, Laurent S, Agabiti-Rosei E, Ambrosioni E, Burnier M, Caufield MJ, et al. Reappraisal of European guidelines on hypertension management: a European Society of Hypertension Task Force document. J Hypertens. 2009;27:2121-58.

72. Staessen JA, Asmar R, De Buyzere M, Imai Y, Parati G, Shimada $\mathrm{K}$, et al. Participants of the 2001 Consensus Conference on Ambulatory Blood Pressure Monitoring. Task Force II. Blood pressure measurement and cardiovascular outcome. Blood Press Monit. 2001;6:355-70.

73. O'Brien E, Asmar R, Beilin L, Imai Y, Mallion JM, Mancia G, et al. European Society of Hypertension Working Group on Blood Pressure Monitoring. European Society of Hypertension recommendations for conventional, ambulatory and home blood pressure measurement. J Hypertens. 2003;21:821-48.

74. Bonow RO, Mitch WE, Nesto RW, O'Gara PT, Becker RC, Clark LT, et al. Prevention conference VI. Diabetes and Cardiovascular disease. Writing Group V: Management of Cardiovascular-Renal Complications. Circulation. 2002;105:159-64.

75. Bakris GL, Williams M, Dworkin L, ElliottWJ, Epstein M, Toto R, et al. Preserving renal function in adults with hypertension and diabetes: a consensus approach. Am J Kidney Dis. 2000;36:646-61.

76. DeFronzo RA. Diabetic nephropathy: etiologic and therapeutic considerations. Diabetes Rev. 1995;3:510-64.

77. Malmberg K, Norhammar A, Wedel H, Ryden L. Glycometabolic state at admission: important risk marker of mortality in conventionally treated patients with diabetes mellitus and acute myocardial infarction: long term results from the Diabetes and Insulin-glucose Infusion in Acute Myocardial Infarction [DIGAMI study] Circulation. 1999;99:2626-32.

78. Colwell JA. Aspirin therapy in diabetes [Technical Review]. Diabetes Care. 1997;20:1767-71.

79. McDonagh TA, Morrison CE, Lawrence A, Ford I, Tunstall-Pedoe $\mathrm{H}$, McMurray JJ, et al. Symptomatic and asymptomatic left ventricular systolic dysfunction in an urban population. Lancet. 1997;350:829-33.

80. Iribarren C, Karter AJ, Go AS, Ferrara A, Liu JY, Sidney S, et al. Glycaemic control and HF among adult patients with diabetes. Circulation. 2001;103:2668-73.

81. Bell DS. Heart failure: the frequent, forgotten and often fatal complication of diabetes. Diabetes Care. 2003;26:2433-41.

82. Marantz PR, Tobin JN, Wassertheil-Smoller S, Steingart RM, Wexler JP, Budner N, et al. The relationship between left ventricular function and congestive HF diagnosed by clinical criteria. Circulation. 1988;77:607-12.

83. Kasrapanayiotides T, Piechowski-Jozwiak B, Van Melle G, Bogousslavsky J, Devuyst G. Stroke patterns, etiology and prognosis in patients with diabetes mellitus. Neurology. 2004;62:1558-62.

84. Megherbi SE, Milan C, Minier D, Couvreur G, Osseby GV, Tilling $\mathrm{K}$, et al. Association between diabetes and stroke subtype on survival and functional outcome 3 months after stroke: data from the European BIOMED Stroke Project. Stroke. 2003;34:688-94.

85. Stevens RJ, Coleman RL, Adler Al, Stratton IM, Matthews DR, Holman RR. Risk factors for myocardial infarction case fatality and stroke case fatality in type 2 diabetes: UKPDS 66. Diabetes Care. 2004;27:201-7.

86. Shepard R, Balady G. Exercise as cardiovascular therapy. Circulation. 1999;99:963-72.

87. American Diabetes Association. Position statement. Diabetes mellitus and exercise. Diabetes Care. 2000;23[suppl 1]:S50-4.

88. Walker KZ, Piers LS, Putt RS, Jones JA, O'Dea K. Effects of regular walking on cardiovascular risk factors and body composition in normoglycaemic woman and woman with type 2 diabetes. Diabetes Care. 1999;22:555-61.

89. Hansson L, Zanchetti A, Carruthers SG, Dahlof B, Elmfeldt D, Julius $\mathrm{S}$, et al. Effects of intensive blood-pressure lowering and 
low-dose aspirin in patients with hypertension: principal results of the Hypertension Optimal Treatment [HOT] randomised trial. Lancet. 1998;351:1755-62.

90. UK Prospective Diabetes Study Group. Tight blood pressure control and risk of macrovascular and microvascular complications in type 2 diabetes: UKPDS 38. BMJ. 1998;317:703-13.

91. Curb JD, Pressel SL, Cutler JA, Savage PJ, Applegate WB, Black $\mathrm{H}$, et al. Effect of diuretic-based antihypertensive treatment on cardiovascular disease risk in older diabetic patients with isolated systolic hypertension. Systolic Hypertension in the Elderly Program Cooperative Research Group. JAMA. 1996;276:1886-92.

92. Tuomilehto J, Rastenyte D, Birkenhäger WH, Thijs L, Antikainen R, Bulpitt CJ, et al. Effects of calcium-channel blockade in older patients with diabetes and systolic hypertension. Systolic Hypertension in Europe Trial Investigators. N Engl J Med. 1999;340:677-84.

93. Estacio RO, Jeffers BW, Gifford N, Schrier RW. Effect of blood pressure control on diabetic microvascular complications in patients with hypertension and type 2 diabetes. Diabetes Care. 2000;23(Suppl 2):S54-64.

94. Heart Outcomes Prevention Evaluation (HOPE) Study investigators. Effects of ramipril on cardiovascular and microvascular outcomes in people with diabetes mellitus: results of the HOPE study and MICROHOPE substudy. Lancet. 2000;355:253-9.

95. Cooper-DeHoff RM, GongY, Handberg EM, Bavry AA, Denardo SJ, Bakris GL, et al. Tight blood pressure control and cardiovascular outcomes among hypertensive patients with diabetes and coronary artery disease. JAMA. 2010:304:61-8.

96. Zanchetti A, Grassi G, Mancia G. When should antihypertensive drug treatment be initiated and to what levels should systolic blood pressure be lowered? A critical reappraisal. J Hypertens. 2009;27:923-34.

97. ACCORD Study group. Effects of intensive blood-pressure control in type 2 diabetes mellitus. N Engl J Med. 2010;362:1575-85.

98. Bangalore S, Kumar S, Lobach I, Messerli FH. Blood pressure targets in subjects with type 2 diabetes mellitus/impaired fasting glucose: observation from traditional and Bayesian random-effects meta-analysis of randomized trials. Circulation. 2011;123:2799-810.

99. Reboldi G, Gentile G, Angeli F, Ambrosio G, Mancia G, Verdecchia $P$. Effects of intensive blood pressure reduction on myocardial infarction and stroke in diabetes: a meta-analysis in 73,913 patients. J Hypertens. 2011;29:1253-169.

100. Patel A, ADVANCE Collaborative Group, MacMahon S, Chalmers J, Neal B, Woodward M, et al. Effects of a fixed combination of perindropil and indapamide on macrovascular and microvascular outcomes in patients with type 2 diabetes mellitus (the ADVANCE trial). Lancet. 2007;370:829-40.

101. Lewis JB. Blood pressure control in chronic kidney disease: is less really more? J Am Soc Nephrol. 2010;21:1086-92.

102. Turnbull F, Neal B, Algert C, Chalmers J, Chapman N, Cutler J, et al.; Blood Pressure Lowering Treatment Trialists' Collaboration. Effects of different blood pressure-lowering regimens on major cardiovascular events in individuals with and without diabetes mellitus: results of prospectively designed overviews of randomized trials. Arch Intern Med. 2005;165:1410-9.

103. Yusuf S, Teo KK, Pogue J, Dyal L, Copland I, Schumacher H, et al.; ONTARGET Investigators. Telmisartan, ramipril, or both in patients at high risk for vascular events. N Engl J Med. 2008;358:1547-59.

104. Jamerson K, Weber MA, Bakris GL, Dahlöf B, Pitt B, Shi V, et al. Benazepril plus amlodipine or hydrochlorothiazide for hypertension in high-risk patients. N Engl J Med. 2008;359:2417-28.

105. U.S. Food and Drug Administration. FDA Drug Safety Communication: New Warning and Contraindication for blood pressure medicines containing aliskiren (Tekturna). Rockville, USA: U.S.
Food and Drug Administration; 2012. [citado 2012 Set 10]. Disponível em: http://www.fda.gov/drugs/drugsafety/ucm300889.htm

106. Stears AJ, Woods SH, Watts M, Burton TJ, Graggaber J, Mir FA, et al. A double-blind, placebo-controlled, crossover trial comparing the effects of amiloride and hydrochlorothiazide on glucose tolerance in patients with essential hypertension. Hypertension. 2012;59:934-42.

107. Central Intelligence Agency-CIA. The World Factbook. Washington, USA: Central Intelligence Agency-CIA; 2012. [citado 2012 Ago 10]. Disponível em: https://www.cia.gov/library/publications/the-world-factbook/wfbExt/region_soa.html

108. Sanchez-Johnsen LA, Fitzgibbon ML, Martinovich Z, Stolley MR, Dyer AR, Van Horn L. Ethnic differences in correlates of obesity between Latin-American and black women. Obes Res. 2004; 12:652-60.

109. Barcelo A, Gregg EW, Partor-Valero M, Robles SC. Waist circumference, $\mathrm{BMI}$ and the prevalence of self-reported diabetes among the elderly of the United States and six cities of Latin American and the Caribbean. Diabetes Res Clin Pract. 2007;78:418-27.

110. Anselmi M, Avanzini F, Moreira JM, Montalvo G, Armani D, Prandi $\mathrm{R}$, et al. Treatment and control of arterial hypertension in a rural community in Ecuador. Lancet. 2003;36:1186-7.

111. Flack JM, Sica DA, Bakris G, Brown AL, Ferdinand KC, Grimm $\mathrm{Jr} \mathrm{RH}$, et al. Management of High Blood Pressure in Blacks. An Update of the International Society on Hypertension in Blacks Consensus Statement on behalf of the International Society on Hypertension in Blacks. Hypertension. 2010;56:780-800.

112. Burke GL, Savage PJ, Manolio TA, Sprafka JM, Wagenknecht LE, Sidney $S$, et al. Correlates of obesity in young black and white women: the CARDIA Study. Am J Public Health. 1992;82:1621-5.

113. Sharp TA, Bell ML, Grunwald GK, Schmitz KH, Sidney S, Lewis $\mathrm{CE}$, et al. Differences in resting metabolic rate between white and African-American young adults. Obes Res. 2002;10:726-32.

114. McVlellan W, Tuttle $E$, Issa A. Racial differences in the incidence of hypertensive end-stage renal disease. Am J Kidney Dis. 1998;12:285-90.

115. Lopes AA, Port FK. The low birth weight hypothesis as a plausible explanation for the black/white differences in hypertension, non-insulin-dependent diabetes, and end-stage renal disease. Am J Kidney Dis. 1995;25:350.

116. Roger VL, Go AS, Lloyd-Jones DM, Adams RJ, Berry JD, Brown TM, et al. Heart diseases and stroke statistics: 2011 update a report from de American Heart Association. Circulation. 2011;123:e18-e209.

117. Sareli P, Radevski IV, Valtchanova ZP, Libhaber E, Candy GP, Den Hond $E$, et al. Efficacy of different drug classes used to initiate antihypertensive treatment in black subjects: results of a randomized trial in Johannesburg, South Africa. Arch Intern Med. 2001;161(7):965-71.

118. Wright JT Jr, Dunn JK, Cutler JA, Davis BR, Cushman WC, Ford $\mathrm{CE}$, et al. Outcomes in hypertensive black and nonblack patients treated with chlorthalidone, amlodipine, and lisinopril. JAMA. 2005;293(13):1595-608.

119. Brown NJ, Ray WA, Snowden M, Griffin MR. Black Americans have an increased rate of angiotensin converting enzyme inhibitor-associated angioedema. Clin PharmacolTher. 1996;60(1):8-13.

120. Medina-Lezama J, Zea-Diaz H, Morey-Vargas OL, Bolaños-Salazar JF, Postigo-Macdowall M, Paredes-Diaz S, et al. Prevalence and patterns of hypertension in Peruvian Andean Hispanics: the PREVENCION study. J Am Soc Hypertens. 2007;1:216-25.

121. Agusti R. Epidemiologia de la hipertensión arterial en el Perú. Acta Med Per. 2006;23(2):69-75.

122. Organización Panamericana de la Salud. Base de Datos de Indicadores Básicos en Salud de la OPS. Washington: OPS; 2007. [citado 
2012 Set 10]. Disponível em: http://www.paho.org/spanish/dd/ais/ cp_152.htm

123. Vasan RS, Beiser A, Seshadri S, Larson MG, Kannel WB, D'Agostino RB, et al. Residual lifetime risk for developing hypertension in middle-aged women and men: the Framingham Heart Study. JAMA. 2002;287:1003-10

124. Benetos A, Safar M, Rudnichi A, Smulyan H, Richard JL, Ducimetiére $P$, et al. Pulse pressure: a predictor of long-term cardiovascular mortality in a French male population. Hypertension. 1997;30:1410-5.

125. Silagy CA, McNeil JJ, Farish S, McGrath BP. Comparation of repeated measurement of ambulatory and clinic blood pressure readings in isolated systolic hypertension. Clin Exp Hypertension. 1995; 15:895-909.

126. Wiinberg N, Hoegholm A, Christensen HR, Bang LE, Mikkelsen KL, Nielsen PE, et al. 24-h-ambulatory blood pressure in 352 normal Danish subjects, related to age and gender. Am J Hypertens. 1995;8:978-86.

127. Kario K, Pickering TG, Matsuo T, Hoshide S, Schwartz JE, Shimada K. Stroke prognosis and abnormal nocturnal blood pressure falls in older hypertensive. Hypertension. 2001;38:852-7.

128. Kario K, Pickering TG, Umeda Y, Hoshide S, Hoshide $Y$, Morinari $M$, et al. Morning surge in blood pressure as a predictor of silent and clinical cerebrovascular disease in elderly hypertensives: a prospective study. Circulation. 2003;107:1401-6.

129. Verdecchia P, Angeli F, Mazzotta G, Garofoli M, Ramundo E, Gentile $G$, et al. Day-night dip and early-morning surge in blood pressure in hypertension: prognostic implications. Hypertension. 2012;60:34-42.

130. Beckett NS, Peters R, Fletcher AE, Staessen JA, Liu L, Dumitrascu D, et al. HYVET Study Group, Treatment of hypertension in patients 80 years of age or older. $\mathrm{N}$ Eng $\mathrm{J}$ Med. 2008;358:1887-98.

131. SHEP Cooperative Research Group. Prevention of stroke by antihypertensive drug treatment in older persons with isolated systolic hypertension. Final results of the Systolic Hypertension in the Elderly Program (SHEP). JAMA. 1991;265(24):3255-64.

132. Staessen JA, Fagard R, Thijs L, Celis H, Arabidze GG, Birkenhäger $\mathrm{WH}$, et al. Randomised double-blind comparison of placebo and active treatment for older patients with isolated systolic hypertension. The Systolic Hypertension in Europe (Syst-Eur) Trial Investigators. Lancet. 1997;350:757-64.
133. Liu L, Wang JG, Gong L, Liu G, Staessen JA. Comparison of active treatment and placebo in older Chinese patients with isolated systolic hypertension, Systolic Hypertension in China (SYST-CHINA) Collaborative Group. J Hypertension. 1998;16:1823-9.

134. Lopez-Jaramillo P, Lahera V, Lopez-Lopez J. Epidemic of cardiometabolic diseases: a Latin American point of view. Ther Adv Cardiovasc Dis. 2011;5:119-31.

135. López-Jaramillo P, Silva SY, Rodríguez Salamanca N, Duran A, Mosquera W, Castillo V. Are nutrition-induced epigenetic changes the link between socioeconomic pathology and cardiovascular diseases? Am JTherap. 2008;15:362-72.

136. López-Jaramillo P. Cardio-metabolic disease in Latin America: the role of fetal programming in response to maternal malnutrition. Rev Esp Cardiol. 2009;62:670-6.

137. Fernandes MT, Sesso R, Martins PA, Sawaya AL. Increased blood pressure in adolescents of socioeconomic status with short stature. Pediatr Nephrol. 2003;18:435-9.

138. Florêncio TT, Ferreira HS, Cavalcante JC, Sawaya AL. Short stature, obesity and arterial hypertension in a very low income population in North-eastern Brazil. Nutr Metab Cardiovasc Dis. 2004;14:26-33.

139. Ferreira HS, Moura FA, Cabral CR Jr, Florêncio TM, Vieira RC, de Assunção ML. Short stature of mothers from an area endemic for under-nutrition is associated with obesity, hypertension and stunted children: a population-based study in the semi-arid region of Alagoas, Northeast Brazil. Br J Nutr. 2009;101:1239-45.

140. López-Jaramillo P, Herrera E, Garcia RG, Camacho PA, Castillo VR. Inter-relationships between body mass index, C-reactive protein and blood pressure in a Hispanic pediatric population. Am J Hypertens. 2008;21:527-32.

141. Franco MC, Casarini DE, Carneiro-Ramos MS, Sawaya AL, Barreto-Chaves ML, Sesso R. Circulating renin-angiotensin system and catecholamines in childhood: is there a role for birth weight? Clin Sci (Lond). 2008:114:375-80.

142. Febba A, Sesso R, Barreto GP, Liboni CS, Franco MC, Casarini DE. Stunting growth: association of the blood pressure levels and ACE activity in early childhood. Pediatr Nephrol. 2009;24:379-86.

143. González-Barranco J, Ríos-Torres JM, Castillo-Martínez L, López-Alvarenga JC, Aguilar-Salinas CA, Bouchard C, et al. Effect of malnutrition during the first year of life on adult plasma insulin and glucose tolerance. Metabolism. 2003;52:1005-11.

144. Lopez-Jaramillo P. Defining the research priorities to fight the burden of cardiovascular diseases in Latin America. J Hypertens. 2008;26:1886-9. 